\title{
PECEIVED
}

SEP $>4007$

OS TI

\section{ERROR ANALYSIS FOR DUCT LEAKAGE TESTS IN ASHRAE STANDARD 152P}

J.W. Andrews .

June 1997

Prepared for:

Building Equipment Division

Office of Building Technologies, State and Community Programs

U.S. Department of Energy

Under Contract No. DE-AC02-76CH00016

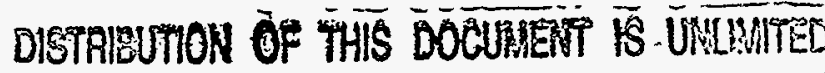
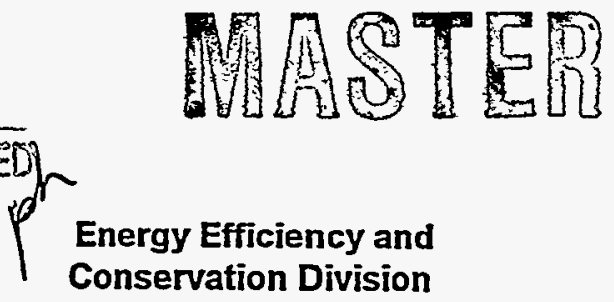

DEPARTMENT OF APPLIED SCIENCE

BROOKHAVEN NATIONAL LABORATORY UPTON, LONG ISLAND, NEW YORK 11973 
BNL- 64679

Informal Report

\section{ERROR ANALYSIS FOR DUCT LEAKAGE TESTS IN ASHRAE STANDARD 152P}

J.W. Andrews

June 1997

Prepared for:

Building Equipment Division

Office of Building Technologies,

State and Community Programs

U.S. Department of Energy

Under Contract No. DE-AC02-76CH00016 


\section{DISCLAIMER}

This report was prepared as an account of work sponsored by the United States Government. Neither the United States nor the United States Department of Energy, nor any of their employees, nor any of their contractors, subcontractors, or their employees, makes any warranty, express or implied, or assumes any legal liability or responsibility for the accuracy, completeness, or usefulness of any information, apparatus, product or process disclosed, or represents that its use would not infringe privately owned rights. 


\section{DISCLAmIER}

Portions of this document may be illegible in electronic image produets. Imsges are produced from the best available original document. 


\section{DISCLAIMER}

This report was prepared as an account of work sponsored by an agency of the United States Government. Neither the United States Government nor any agency thereof, nor any of their employees, make any warranty, express or implied, or assumes any legal liability or responsibility for the accuracy, completeness, or usefulness of any information, apparatus, product, or process disclosed, or represents that its use would not infringe privately owned rights. Reference herein to any specific commercial product, process, or service by trade name, trademark, manufacturer, or otherwise does not necessarily constitute or imply its endorsement, recommendation, or favoring by the United States Government or any agency thereof. The views and opinions of authors expressed herein do not necessarily state or reflect those of the United States Government or any agency thereof. 


\title{
ERROR ANALYSIS FOR DUCT LEAKAGE TESTS IN ASHRAE STANDARD 152P
}

\author{
J. W. Andrews \\ Energy Efficiency and Conservation Division \\ Department of Applied Science \\ Brookhaven National Laboratory
}

June 1997

\author{
Prepared for: \\ Building Equipment Division \\ Office of Building Technologies, \\ State and Community Programs \\ U.S. Department of Energy \\ Under Contract No. DE-AC02-76CH00016
}




\section{Table of Contents}

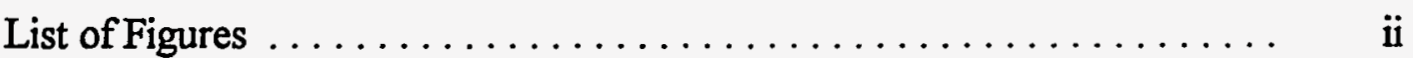

List of Tables .......................... ii

Abstract $\ldots \ldots \ldots \ldots \ldots \ldots \ldots \ldots \ldots \ldots \ldots \ldots \ldots \ldots \ldots \ldots \ldots \ldots$ iii

Introduction $\ldots \ldots \ldots \ldots \ldots \ldots \ldots \ldots \ldots \ldots \ldots \ldots \ldots \ldots \ldots, \quad 1$

Organization of The Report $\ldots \ldots \ldots \ldots \ldots \ldots \ldots \ldots \ldots \ldots \ldots$

The House Pressure Test $\ldots \ldots \ldots \ldots \ldots \ldots \ldots \ldots \ldots \ldots \ldots \ldots \ldots \ldots \ldots$

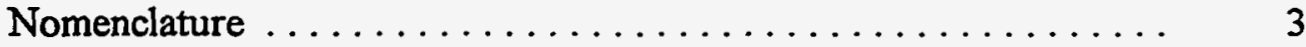

Equations for Duct Leakage ..................... 4

Derivative of a Special Function. .................. 5

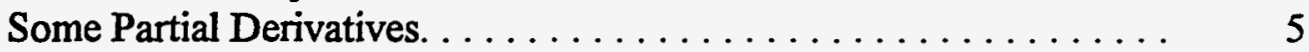

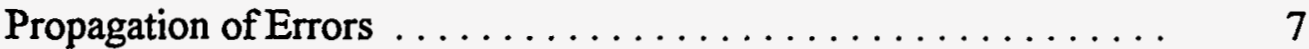

Addition in Quadrature ....................... 9

Pathological Behavior of Functions $f, g, h \ldots \ldots \ldots \ldots \ldots .12$

A Criterion of Allowable Error ................... 12

Allowable Errors in the Six Independent Variables ........... 15

Summary .............................. 20

Fan Pressurization Test ........................... 22

Nomenclature ................................ 24

Relationships Among the Leakages . . . . . . . . . . . . . . $\quad 24$

Error Propagation . . . . . . . . . . . . . . . . . . . . . $\quad 25$

Allowable Errors . . . . . . . . . . . . . . . . . . . . . 28

Application of the Allowable-Error Criterion . . . . . . . . . $\quad 30$

Summary ............................. 34

References. ................................... 35

Appendix 1. Pathological Behavior of Functions $f, g$, and $h . \ldots \ldots \ldots . . \ldots$ 


\section{List of Figures}

1. Schematic of the House Pressure Test for Duct Leakage .......... 2

2. Schematic of the Fan Pressurization Test for Duct Leakage ........ 23

A-1. Behavior of the f-Function vs. $\Delta \mathrm{P}_{\text {off }}$ for Various Values of $\Delta \mathrm{P}_{\mathrm{on}} \ldots \ldots \quad 38$

A-2. Ratio of $f\left(\Delta P_{\text {on }}\right)$ to the Average Value of $f$ over the Range $\Delta P_{o n}-0.2$ to $\Delta P_{o n}+0.2 \ldots \ldots \ldots \quad 38$

A-3. Behavior of $g_{s} v s . \Delta P_{\text {off }}$ for Various Values of $\Delta P_{R B}$, with $\Delta \mathrm{P}_{\text {on }}$ Fixed at $-1 \mathrm{~Pa} \ldots \ldots \ldots \ldots . \quad 40$

A-4. Behavior of $g_{R}$ vs. for Various Values of $\Delta P_{R B}$, with $\Delta \mathrm{P}_{\text {on }}$ Fixed at $-1 \mathrm{~Pa} . \ldots \ldots \ldots . \quad 41$

\section{List of Tables}

1. Allowed Errors in Independent Variables of House Pressure Test for Duct Leakage. ............ $\quad 21$

2. Allowed Errors in Independent Variables of

Fan Pressurization Test for Duct Leakage . . . . . . . . . . 34 


\begin{abstract}
This report presents an analysis of random uncertainties in the two methods of testing for duct leakage in Standard 152P of the American Society of Heating, Refrigerating, and Air-Conditioning Engineers (ASHRAE). The test method is titled Standard Method of Test for Determining SteadyState and Seasonal Efficiency of Residential Thermal Distribution Systems. Equations have been derived for the uncertainties in duct leakage for given levels of uncertainty in the measured quantities used as inputs to the calculations. Tables of allowed errors in each of these independent variables, consistent with fixed criteria of overall allowed error, have been developed.
\end{abstract}




\section{INTRODUCTION}

The purpose of this report is to analyze measurement errors in the two tests for duct leakage that are central to the new Standard Method of Test for Determining Steady-State and Seasonal Efficiency of Residential Thermal Distribution Systems, currently being developed under the auspices of the American Society of Heating, Refrigerating, and Air-Conditioning Engineers, Inc. (ASHRAE). The test method has been designated by ASHRAE as Standard 152P. [ASHRAE 1997] Standard 152P accounts for all mechanisms of energy loss in duct systems, including interactions of the duct system with the building envelope and with the heating or cooling equipment. But the heart of the standard, and the only energy-loss quantity that is measured directly, is duct leakage.

One of the two duct leakage tests, which is generally referred to as the "house pressure test," was developed by Dr. Mark P. Modera of Lawrence Berkeley National Laboratory.[Modera and Byrne 1997] The derivation of the method, as yet unpublished, was provided to the author of this report and is discussed herein. The second duct leakage test is the more traditional one that relies on fan-pressurization of the duct system. Both tests measure duct leakage to zones outside the conditioned space.

It is important to recall at the outset the distinction between random uncertainty and systematic bias. Random uncertainties are caused by measurement errors that vary unpredictably between trials but have an expected value of zero. Systematic bias is the component of measurement error that is the same for all trials. The scope of this report is limited to random uncertainties. Accordingly, the term "error," where it is used without qualification, should be understood to mean random uncertainty.

\section{ORGANIZATION OF THE REPORT}

The report is divided into two major sections, the first dealing with the house pressure test and the second with the fan pressurization test for duct leakage. Within each section, the equations for error propagation are developed. These permit the random uncertainties in the supply- and return-duct leakage rates to be calculated from known or postulated random uncertainties in the measured quantities that serve as inputs to the leakage calculations. Following this, a criterion of allowable error in duct leakage is developed and used to calculate the allowable error in each of these measured quantities. An engineering judgment of the difficulty of attaining the required level of precision for each measured quantity is then made and explained.

For the house pressure test, the error-propagation relations are given in Equation 24 for supply leakage and Equation 25 for return leakage. The allowable errors are summarized in Table 1. For the fan-pressurization duct leakage test, the error-propagation relations are given in Equation 45, which applies to both the supply and return sides. The allowable errors are summarized in Table 2 . 


\section{THE HOUSE PRESSURE TEST}

The house pressure test is a relatively new way of measuring duct leakage.[Modera and Byrne 1997] It uses the house envelope itself as a standard of leakage with which the leakiness of the duct system is compared. It requires a measurement of the envelope flow coefficient, using a blower door, and several series of measurements of the pressure difference between the house and the attic under various operating conditions, together with measurements of the pressures in the supply and return ducts (Figure 1). These pressure measurements are accomplished using a digital manometer and a set of plastic hoses. Assuming that the blower door test has already been done for other reasons, the house pressure test can usually be accomplished in less than an hour.

The procedure is as follows. First, measure the flow coefficient of the house envelope with a blower door. A blower door is a calibrated fan installed in a doorway and used to establish a pressure difference between the living space and the outside. A single-point measurement (such as CFM25) is acceptable to the standard, which assumes $N=0.65$ in the relationship (flow) $\propto$ (pressure) $^{N}$. Next, run a plastic hose up into the attic and attach the other end to the reference port of a manometer located within the conditioned space. Run another plastic hose into the return duct so that its end is approximately midway (within $1 \mathrm{~m}[3 \mathrm{ft}]$ of the midpoint) between the register and the return plenum and attach the other end to the input port of a manometer located within the conditioned space. If the filter is at the furnace, it is removed and the filter access sealed. Another plastic tube is connected to a pressure pan, which is located near a supply register that is chosen for its nearness to the main supply trunk.

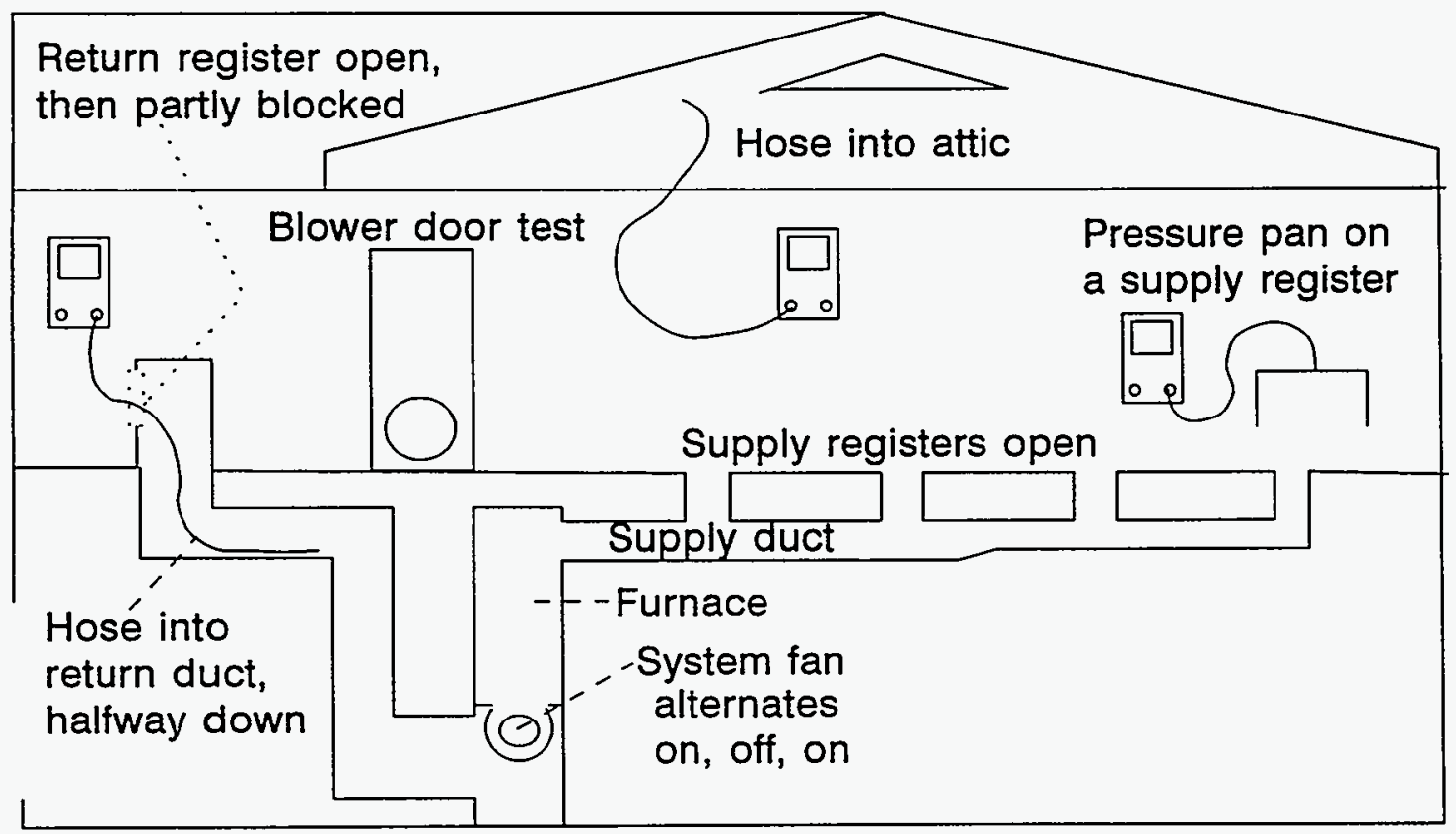

Figure 1. Schematic of the House Pressure Test for Duct Leakage 
With these preliminaries out of the way, the furnace fan is turned on and allowed to come up to speed. The house-attic pressure difference $(\Delta \mathrm{P})$ is measured ten times. The $\Delta \mathrm{P}$ between the return duct and the house is measured once. Next, the furnace fan is turned off and allowed to stop. The house-attic $\Delta \mathrm{P}$ is measured ten times. The furnace fan is turned on again. The house-attic $\Delta \mathrm{P}$ is measured ten times, the $\Delta \mathrm{P}$ between the return duct and the house is measured once, and then, using the pressure pan, the $\Delta \mathrm{P}$ between the chosen supply register and the house is measured once. Again the furnace fan is turned off, and the house-attic $\Delta \mathrm{P}$ is measured ten times.

At this point the second phase of the test begins. Here, the operating conditions of the system are deliberately altered by turning the furnace fan on and blocking the return register(s) with a piece of paper or cardboard until the $\Delta \mathrm{P}$ between the return duct and the house is approximately $-100 \mathrm{~Pa}$, or until the register(s) are completely covered if this pressure cannot be reached. The house-attic $\Delta \mathrm{P}$ is measured ten times. The $\Delta \mathrm{P}$ between the return duct and the house is measured once, and then, using the pressure pan again, the $\Delta \mathrm{P}$ between the chosen supply register and the house is measured once. Finally, the fan is turned off and the house-attic $\Delta \mathrm{P}$ is measured ten more times. These data are then input to a set of equations that yield values of supply and return leakage to the outside under normal operating conditions. The source of these equations and the propagation of errors within them will now be discussed.

\section{Nomenclature}

The following notation will be used in this discussion. In some cases it is shortened relative to what is in the current Standard 152P draft; in such cases the 152P notation is given in parentheses.

$Q_{s} \quad$ Air leakage rate from supply ducts to the outside under normal operation

$Q_{r} \quad$ Air leakage rate from the outside to the return ducts under normal operation

$\mathrm{Q}_{\mathrm{sr}} \quad$ Algebraic sum of supply $(+)$ and return (-) leaks under normal operation, with return not blocked $\left(\mathrm{Q}_{\text {sleakt+rleak }}\right.$ in $\left.152 \mathrm{P}\right)$

$Q_{\text {srRB }} \quad$ Algebraic sum of supply and return leaks with return blocked $\left(Q_{\text {steaktrleakRB }}\right.$ in SPC152)

$\mathrm{K}$ Envelope flow coefficient ( $\mathrm{C}_{\text {env }}$ in $\left.152 \mathrm{P}\right)$

$\mathrm{K}_{\mathrm{s}} \quad$ Supply-duct flow coefficient

$\mathrm{K}_{\mathrm{T}} \quad$ Return-duct flow coefficient

$\Delta \mathrm{P}_{\text {on }} \quad$ House-attic pressure difference with fan on (may be $>0$ or $<0$ )

$\Delta \mathrm{P}_{\text {off }}$ House-attic pressure difference with fan off (may be $>0$ or $<0$ )

$\Delta \mathrm{P}_{\mathrm{RB}} \quad$ House-attic pressure difference with fan on and return partially blocked (usually $<0$ )

$\Delta \mathrm{P}_{\mathrm{r}} \quad$ House-return pressure difference with fan on (assumed $\left.>0\right)\left(\left|\Delta \mathrm{P}_{\mathrm{ret}}\right|\right.$ in 152P)

$\Delta \mathrm{P}_{\mathrm{rRB}}$ House-return pressure difference with fan on and return partially blocked (assumed $>0$ ) $\left(\left|\Delta \mathrm{P}_{\text {retRB }}\right|\right.$ in $\left.152 \mathrm{P}\right)$

$\Delta \mathrm{P}_{\mathrm{s}} \quad$ Supply-house pressure difference with fan on (assumed $\left.>0\right)\left(\Delta \mathrm{P}_{\text {supon }}\right.$ in $\left.152 \mathrm{P}\right)$

$\Delta \mathrm{P}_{\mathrm{sRB}}$ Supply-house pressure difference with fan on and return partially blocked (assumed $>0$ ) $\left(\triangle \mathrm{P}_{\text {supRB }}\right.$ in $\left.152 \mathrm{P}\right)$

$\mathrm{n} \quad$ Envelope flow exponent, generally taken to equal $0.65\left(\mathrm{n}_{\mathrm{env}}\right.$ in $\left.152 \mathrm{P}\right)$

nduct Duct flow exponent, generally taken to equal 0.60 (written as a number in 152P) 


\section{Equations for Duct Leakage in the House Pressure Test}

The derivation due to Mark Modera sets the net leakage from the ducts to the outside equal to the net inflow of air across the envelope, so that the amount of air in the house remains constant. The pressure across the ceiling (living space with respect to attic) when the fan is on is $\Delta \mathrm{P}_{\text {or }}$. The pressure across the floor when the fan is on is developed by assuming that the difference in pressure under the floor, relative to that above the ceiling, is the same when the fan is on as when it is off, because the driving forces (stack and wind) have not changed. In that case, the pressure under the floor, relative to that inside, is $2 \Delta \mathrm{P}_{\text {off }}-\Delta \mathrm{P}_{\text {on }}$. The same relations would hold when the return is blocked, with the addition of RB to the subscripts. The equations as they appear in SPC152P are:

$$
\begin{gathered}
Q_{s r}=\frac{1}{2} K\left[\operatorname{sign}\left(2 \Delta P_{o f f}-\Delta P_{o n}\right)\left|2 \Delta P_{o f f}-\Delta P_{o n}\right|^{n}-\operatorname{sign}\left(\Delta P_{o n}\right)\left|\Delta P_{o n}\right|^{n}\right] \\
Q_{s r R B}=\frac{1}{2} K\left[\operatorname{sign}\left(2 \Delta P_{o f f}-\Delta P_{R B}\right)\left|2 \Delta P_{o f f}-\Delta P_{R B}\right|^{n}-\operatorname{sign}\left(\Delta P_{R B}\right)\left|\Delta P_{R B}\right|^{n}\right]
\end{gathered}
$$

These two quantities can be calculated using the measured values of the pressure differences and the envelope flow coefficient. Therefore, in what follows $Q_{s r}$ and $Q_{s r R B}$ can be taken as known quantities. It is unnecessary to carry along the right-hand sides with all their complexity.

The next step in Modera's analysis is to express $Q_{s t}$ and $Q_{s R B}$ in terms of the duct leakage flow coefficients and operating pressures:

$$
\begin{gathered}
Q_{s r}=K_{s} \Delta P_{s}^{n d u c t}-K_{r} \Delta P_{r}^{n d u c t} \\
Q_{s r R B}=K_{s} \Delta P_{s R B}^{\text {nduct }}-K_{r} \Delta P_{r R B}^{\text {nduct }}
\end{gathered}
$$

These two equations can then be solved for $K_{s}$ and $K_{r}$ in terms of $Q_{s r} Q_{s R B}$ and the $\Delta P$ 's, all of which are measured quantities or calculated from measured quantities:

$$
K_{r}=\frac{\Delta P_{s R B}^{n d u c t} Q_{s r}-\Delta P_{s}^{\text {nduct }} Q_{s r R B}}{\Delta P_{s}^{n d u c t} \Delta P_{r R B}^{\text {nduct }}-\Delta P_{s R B}^{\text {nduct }} \Delta P_{r}^{\text {nduct }}}
$$




$$
K_{s}=\frac{\Delta P_{r R B}^{n d u c t} Q_{s r}-\Delta P_{r}^{\text {nduct }} Q_{s r R B}}{\Delta P_{s}^{\text {nduct }} \Delta P_{r R B}^{\text {nduct }}-\Delta P_{s R B}^{\text {nduct }} \Delta P_{r}^{\text {nduct }}}
$$

If we now let $\mathrm{S}=\left(\Delta \mathrm{p}_{\mathrm{sRB}} / \Delta \mathrm{P}_{\mathrm{s}}\right)^{\text {nduct }}$ and $\mathrm{R}=\left(\Delta \mathrm{p}_{\mathrm{rRB}} / \Delta \mathrm{P}_{\mathrm{r}}\right)^{\text {nduet }}$, and recognize that $\mathrm{Q}_{\mathrm{s}}=\mathrm{K}_{\mathrm{s}}\left(\Delta \mathrm{P}_{\mathrm{s}}\right)^{\text {nduct }}$ and $\mathrm{Q}_{\mathrm{r}}=-\mathrm{K}_{\mathrm{r}}\left(\Delta \mathrm{P}_{\mathrm{r}}\right)^{\text {nduct }}$, the minus sign in the latter expression to make $\mathrm{Q}_{\mathrm{r}}$ negative, then Equations 5 and 6 become:

$$
\begin{aligned}
& Q_{r}=\frac{-S Q_{s r}+Q_{s r R B}}{R-S} \\
& Q_{s}=\frac{R Q_{s r}-Q_{s r R B}}{R-S}
\end{aligned}
$$

These equations may be subject to systematic bias caused by possible failure of real houses to live up to the underlying theoretical assumptions. As stated in the Introduction, such systematic bias, if it exists, is beyond the scope of this report, which considers random uncertainty only.

\section{Derivative of a Special Function}

In the error analysis, we will need the derivative of quantities of the somewhat complicated form $f(x)=\operatorname{sign}(x)|x|^{n}$. If the first derivative with respect to $x$ is denoted $f^{\prime}(x)$, then:

$$
\begin{aligned}
& \text { If } x>0 \quad f(x)=x^{n} \quad \text { and hence } \quad f^{\prime}(x)=n x^{n-1} \\
& \text { If } x<0 \quad f(x)=-(-x)^{n} \quad \text { and hence } \quad f^{\prime}(x)=-n(-x)^{n-1}(-1) \\
& =n(-x)^{n-1}
\end{aligned}
$$

If $x=0$ and $n<1$, the derivative is undefined. Since in our case $n \approx 0.65$, we have to deal with the fact that the derivative becomes unbounded (i.e. blows up to infinity) as $\mathrm{x}$ approaches zero. If $x \neq 0$, however, the derivative is well-behaved and can be generically written as $f^{\prime}(x)=n|x|^{n-1}$.

\section{Some Partial Derivatives}

The first steps in deriving the equations for the errors in $\mathrm{Q}_{s}$ and $\mathrm{Q}_{\mathrm{r}}$ are to take the partial derivatives of $\mathrm{Q}_{\mathrm{sr}}$ and $\mathrm{Q}_{\mathrm{srRB}}$ with respect to $\Delta \mathrm{P}_{\mathrm{on}}, \Delta \mathrm{P}_{\text {off }}$, and $\Delta \mathrm{P}_{\mathrm{RB}}$ : 


$$
\begin{aligned}
& \frac{\partial Q_{s r}}{\partial \Delta P_{o n}}=-\frac{1}{2} K n\left[\left|2 \Delta P_{o f f}-\Delta P_{o n}\right|^{n-1}+\left|\Delta P_{o n}\right|^{n-1}\right] \\
& \frac{\partial Q_{s r}}{\partial \Delta P_{o f f}}=K n\left|2 \Delta P_{o f f}-\Delta P_{o n}\right|^{n-1} \\
& \frac{\partial Q_{s r}}{\partial \Delta P_{R B}}=0 \\
& \frac{\partial Q_{s r R B}}{\partial \Delta P_{o n}}=0 \\
& \frac{\partial Q_{s r R B}}{\partial \Delta P_{o f f}}=K n\left|2 \Delta P_{o f f}-\Delta P_{R B}\right|^{n-1} \\
& \frac{\partial Q_{s r R B}}{\partial \Delta P_{R B}}=-\frac{1}{2} K n\left[\left|2 \Delta P_{o f f}-\Delta P_{R B}\right|^{n-1}+\left|\Delta P_{R B}\right|^{n-1}\right]
\end{aligned}
$$

We also need the partials of $Q_{s}$ and $Q_{r}$ with respect to $Q_{s r}$ and $Q_{s r R B}$ :

$$
\begin{aligned}
\frac{\partial Q_{s}}{\partial Q_{s r}} & =\frac{R}{R-S} \\
\frac{\partial Q_{s}}{\partial Q_{s r R B}} & =-\frac{1}{R-S} \\
\frac{\partial Q_{r}}{\partial Q_{s r}} & =-\frac{S}{R-S} \\
\frac{\partial Q_{r}}{\partial Q_{s r R B}} & =\frac{1}{R-S}
\end{aligned}
$$




\section{Propagation of Errors}

In order to determine how the errors propagate, we make use of the chain rule for partial derivatives. The functional structure of $\mathrm{Q}_{5}$ or $\mathrm{Q}_{\mathrm{r}}$ (written generically as $\mathrm{Q}$ ) vs. the independent and intermediate variables can be expressed as:

$$
\begin{gathered}
Q=f_{1}\left(Q_{s r}, Q_{s r R B}, R, S\right) \\
Q_{s r}=f_{2}\left(\Delta P_{o n}, \Delta P_{o f f}, \Delta P_{R B}\right) \\
Q_{s r R B}=f_{3}\left(\Delta P_{o n}, \Delta P_{o f f} \Delta P_{R B}\right)
\end{gathered}
$$

Since $\mathrm{Q}_{\mathrm{sr}}$ and $\mathrm{Q}_{\mathrm{sRB}}$ are functions of $\Delta \mathrm{P}_{\text {on }}, \Delta \mathrm{P}_{\text {off }}$ and $\Delta \mathrm{P}_{\mathrm{RB}}$, but $\mathrm{R}$ and $\mathrm{S}$ are not functions of these variables, we may write for $Q_{s}$ :

$$
\begin{gathered}
\frac{\partial Q_{s}}{\partial \Delta P_{o n}}=\frac{\partial Q_{s}}{\partial Q_{s r}} \frac{\partial Q_{s r}}{\partial \Delta P_{o n}}+\frac{\partial Q_{s}}{\partial Q_{s r R B}} \frac{\partial Q_{s r R B}}{\partial \Delta P_{o n}} \\
\frac{\partial Q_{s}}{\partial \Delta P_{o f f}}=\frac{\partial Q_{s}}{\partial Q_{s r}} \frac{\partial Q_{s r}}{\partial \Delta P_{o f f}}+\frac{\partial Q_{s}}{\partial Q_{s r R B}} \frac{\partial Q_{s r R B}}{\partial \Delta P_{o f f}} \\
\frac{\partial Q_{s}}{\partial \Delta P_{R B}}=\frac{\partial Q_{s}}{\partial Q_{s r}} \frac{\partial Q_{s r}}{\partial \Delta P_{R B}}+\frac{\partial Q_{s}}{\partial Q_{s r R B}} \frac{\partial Q_{s r R B}}{\partial \Delta P_{R B}}
\end{gathered}
$$

and for $Q_{r}$ :

$$
\begin{gathered}
\frac{\partial Q_{r}}{\partial \Delta P_{o n}}=\frac{\partial Q_{r}}{\partial Q_{s r}} \frac{\partial Q_{s r}}{\partial \Delta P_{o n}}+\frac{\partial Q_{r}}{\partial Q_{s r R B}} \frac{\partial Q_{s r R B}}{\partial \Delta P_{o n}} \\
\frac{\partial Q_{r}}{\partial \Delta P_{\text {off }}}=\frac{\partial Q_{r}}{\partial Q_{s r}} \frac{\partial Q_{s r}}{\partial \Delta P_{\text {off }}}+\frac{\partial Q_{r}}{\partial Q_{s r R B}} \frac{\partial Q_{s r R B}}{\partial \Delta P_{\text {off }}} \\
\frac{\partial Q_{r}}{\partial \Delta P_{R B}}=\frac{\partial Q_{r}}{\partial Q_{s r}} \frac{\partial Q_{s r}}{\partial \Delta P_{R B}}+\frac{\partial Q_{r}}{\partial Q_{s r R B}} \frac{\partial Q_{s r R B}}{\partial \Delta P_{R B}}
\end{gathered}
$$

which is the same set of equations but with $Q_{r}$ substituted for $Q_{s}$ wherever it occurs. 
We can now write the partial derivatives of $\mathrm{Qs}$ with respect to $\Delta \mathrm{P}_{\text {on }}, \Delta \mathrm{P}_{\text {off }} \Delta \mathrm{P}_{\mathrm{RB}}$ :

$$
\begin{aligned}
\frac{\partial Q_{s}}{\partial \Delta P_{o n}} & =-\frac{R K n}{2(R-S)}\left[\left|2 \Delta P_{\text {off }}-\Delta P_{o n}\right|^{n-1}+\left|\Delta P_{o n}\right|^{n-1}\right] \\
\frac{\partial Q_{s}}{\partial \Delta P_{\text {off }}} & =\frac{K n}{(R-S)}\left[-\left|2 \Delta P_{\text {off }}-\Delta P_{R B}\right|^{n-1}+R\left|2 \Delta P_{o f f}-\Delta P_{o n}\right|^{n-1}\right] \\
\frac{\partial Q_{s}}{\partial \Delta P_{R B}} & =\frac{K n}{2(R-S)}\left[\left|2 \Delta P_{\text {off }}-\Delta P_{R B}\right|^{n-1}+\left|\Delta P_{R B}\right|^{n-1}\right] \\
\frac{\partial Q_{s}}{\partial S} & =\frac{-\left(R Q_{s r}-Q_{s r R B}\right)(-1)}{(R-S)^{2}}=\frac{Q_{s}}{(R-S)} \\
\frac{\partial Q_{s}}{\partial R} & =\frac{-S Q_{s r}+Q_{s r R B}}{(R-S)^{2}}=\frac{Q_{r}}{(R-S)}
\end{aligned}
$$

and the same partials for Qr:

$$
\begin{aligned}
\frac{\partial Q_{r}}{\partial \Delta P_{o n}} & =\frac{S K n}{2(R-S)}\left[\left|2 \Delta P_{o f f}-\Delta P_{o n}\right|^{n-1}+\left|\Delta P_{o n}\right|^{n-1}\right] \\
\frac{\partial Q_{r}}{\partial \Delta P_{o f f}} & =\frac{K n}{(R-S)}\left[\left|2 \Delta P_{o f f}-\Delta P_{R B}\right|^{n-1}-S\left|2 \Delta P_{o f f}-\Delta P_{o n}\right|^{n-1}\right] \\
\frac{\partial Q_{r}}{\partial \Delta P_{R B}} & =-\frac{K n}{2(R-S)}\left[\left|2 \Delta P_{o f f}-\Delta P_{R B}\right|^{n-1}+\left|\Delta P_{R B}\right|^{n-1}\right] \\
\frac{\partial Q_{r}}{\partial S} & =\frac{\left.-R Q_{s r}+Q_{s r R B}\right)}{(R-S)^{2}}=-\frac{Q_{s}}{(R-S)} \\
\frac{\partial Q_{r}}{\partial R} & =-\frac{-S Q_{s r}+Q_{s r R B}}{(R-S)^{2}}=-\frac{Q_{r}}{(R-S)}
\end{aligned}
$$


As for the dependence on $\mathrm{K}$, it should be noted that $\mathrm{Q}_{\mathrm{s}}$ and $\mathrm{Q}_{\mathrm{sRB}}$ are proportional to $\mathrm{K}$, and that $Q_{s}$ and $Q_{r}$ are linear combinations of $Q_{S}$ and $Q_{s R B}$ and hence also proportional to $K$. This implies:

$$
\begin{aligned}
& \frac{\partial Q_{s}}{\partial K}=\frac{Q_{s}}{K} \\
& \frac{\partial Q_{r}}{\partial K}=\frac{Q_{r}}{K}
\end{aligned}
$$

Let us now express the differentials of $Q_{s}$ and $Q_{r}$ in terms of the differentials of the independent variables and the appropriate partial derivatives:

$$
\begin{aligned}
d Q_{s}=\frac{\partial Q_{s}}{\partial \Delta P_{\text {on }}} d \Delta P_{\text {on }} & +\frac{\partial Q_{s}}{\partial \Delta P_{\text {off }}} d \Delta P_{\text {off }}+\frac{\partial Q_{s}}{\partial \Delta P_{R B}} d \Delta P_{R B}+ \\
& +\frac{\partial Q_{s}}{\partial R} d R+\frac{\partial Q_{s}}{\partial S} d S+\frac{\partial Q_{s}}{\partial K} d K
\end{aligned}
$$

and

$$
\begin{aligned}
d Q_{r}=\frac{\partial Q_{r}}{\partial \Delta P_{o n}} d \Delta P_{o n} & +\frac{\partial Q_{r}}{\partial \Delta P_{\text {off }}} d \Delta P_{\text {off }}+\frac{\partial Q_{r}}{\partial \Delta P_{R B}} d \Delta P_{R B}+ \\
& +\frac{\partial Q_{r}}{\partial R} d R+\frac{\partial Q_{r}}{\partial S} d S+\frac{\partial Q_{r}}{\partial K} d K
\end{aligned}
$$

\section{Addition in Quadrature}

We now identify the random uncertainty in any independent variable (defined in any consistent way, such as one standard deviation, $95 \%$ confidence limit, etc.) with the differential of that variable. We further assume that the errors are not correlated in any way. Finally, we will use the notation errX to mean the consistently defined root-mean-square random uncertainty in any quantity $\mathrm{X}$. Under these conditions we may write for the error in $Q_{s}$ : 


$$
\begin{aligned}
e r r Q_{s}= & {\left[\left(\frac{\partial Q_{s}}{\partial \Delta P_{\text {on }}}\right)^{2}\left(e r r \Delta P_{\text {on }}\right)^{2}+\left(\frac{\partial Q_{s}}{\partial \Delta P_{\text {off }}}\right)^{2}\left(e r r \Delta P_{\text {off }}\right)^{2}+\left(\frac{\partial Q_{s}}{\partial \Delta P_{R B}}\right)^{2}\left(e r r \Delta P_{R B}\right)^{2}+\right.} \\
& \left.+\left(\frac{\partial Q_{s}}{\partial R}\right)^{2}(e r r R)^{2}+\left(\frac{\partial Q_{s}}{\partial S}\right)^{2}(e r r S)^{2}+\left(\frac{\partial Q_{s}}{\partial K}\right)^{2}(e r r K)^{2}\right]^{1 / 2}
\end{aligned}
$$

and for the error in $Q_{r}$ :

$$
\begin{aligned}
e r r Q_{r}= & {\left[\left(\frac{\partial Q_{r}}{\partial \Delta P_{\text {on }}}\right)^{2}\left(e r r \Delta P_{\text {on }}\right)^{2}+\left(\frac{\partial Q_{r}}{\partial \Delta P_{\text {off }}}\right)^{2}\left(e r r \Delta P_{\text {off }}\right)^{2}+\left(\frac{\partial Q_{r}}{\partial \Delta P_{R B}}\right)^{2}\left(e r r \Delta P_{R B}\right)^{2}+\right.} \\
& \left.+\left(\frac{\partial Q_{r}}{\partial R}\right)^{2}(e r r R)^{2}+\left(\frac{\partial Q_{r}}{\partial S}\right)^{2}(e r r S)^{2}+\left(\frac{\partial Q_{r}}{\partial K}\right)^{2}(e r r K)^{2}\right]^{1 / 2}
\end{aligned}
$$

Substituting then the partial derivatives from Equation 14 into Equation 19, we obtain:

$$
\begin{aligned}
& \operatorname{err} Q_{s}=\left[\left(\frac{R K n}{2(R-S)}\right)^{2}\left(\left|2 \Delta P_{\text {off }}-\Delta P_{o n}\right|^{n-1}+\left|\Delta P_{o n}\right|^{n-1}\right)^{2}\left(e r r \Delta P_{o n}\right)^{2}+\right. \\
& +\left(\frac{K n}{(R-S)}\right)^{2}\left(-\left|2 \Delta P_{\text {off }}-\Delta P_{R B}\right|^{n-1}+R\left|2 \Delta P_{\text {off }}-\Delta P_{\text {on }}\right|^{n-1}\right)^{2}\left(e r r \Delta P_{\text {off }}\right)^{2}+ \\
& +\left(\frac{K n}{2(R-S)}\right)^{2}\left(\left|2 \Delta P_{\text {off }}-\Delta P_{R B}\right|^{n-1}+\left|\Delta P_{R B}\right|^{n-1}\right)^{2}\left(e r r \Delta P_{R B}\right)^{2}+ \\
& \left.+\left(\frac{Q_{r}}{(R-S)}\right)^{2}(e r r R)^{2}+\left(\frac{Q_{s}}{(R-S)}\right)^{2}(e r r S)^{2}+\left(\frac{Q_{s}}{K}\right)^{2}(e r r K)^{2}\right]^{1 / 2}
\end{aligned}
$$


and similarly, substituting partial derivatives from Equation 15 into Equation 20 we get:

$$
\begin{aligned}
& e r r Q_{r}=\left[\left(\frac{S K n}{2(R-S)}\right)^{2}\left(\left|2 \Delta P_{\text {off }}-\Delta P_{\text {on }}\right|^{n-1}+\left|\Delta P_{\text {on }}\right|^{n-1}\right)^{2}\left(e r r \Delta P_{\text {on }}\right)^{2}+\right. \\
& +\left(\frac{K n}{(R-S)}\right)^{2}\left(\left|2 \Delta P_{\text {off }}-\Delta P_{R B}\right|^{n-1}-S\left|2 \Delta P_{\text {off }}-\Delta P_{\text {on }}\right|^{n-1}\right)^{2}\left(e r r \Delta P_{\text {off }}\right)^{2}+ \\
& +\left(\frac{K n}{2(R-S)}\right)^{2}\left(\left|2 \Delta P_{o f f}-\Delta P_{R B}\right|^{n-1}+\left|\Delta P_{R B}\right|^{n-1}\right)^{2}\left(e r r \Delta P_{R B}\right)^{2}+ \\
& \left.+\left(\frac{Q_{r}}{(R-S)}\right)^{2}(e r r R)^{2}+\left(\frac{Q_{s}}{(R-S)}\right)^{2}(e r r S)^{2}+\left(\frac{Q_{r}}{K}\right)^{2}(e r r K)^{2}\right]^{1 / 2}
\end{aligned}
$$

These equations can be given a simpler appearance if the expressions involving the three $\Delta \mathrm{P}^{\prime} \mathrm{s}$ raised to the $\mathrm{n}-1$ power are grouped into single symbols:

$$
\begin{aligned}
f & =\left|2 \Delta P_{\text {off }}-\Delta P_{\text {on }}\right|^{n-1}+\left|\Delta P_{\text {on }}\right|^{n-1} \\
g_{R} & =\left|\left(-\left|2 \Delta P_{\text {off }}-\Delta P_{R B}\right|^{n-1}+R\left|2 \Delta P_{\text {off }}-\Delta P_{\text {on }}\right|^{n-1}\right)\right| \\
g_{S} & =\left|\left(\left|2 \Delta P_{\text {off }}-\Delta P_{R B}\right|^{n-1}-S\left|2 \Delta P_{\text {off }}-\Delta P_{\text {on }}\right|^{n-1}\right)\right| \\
h & =\left|2 \Delta P_{\text {off }}-\Delta P_{R B}\right|^{n-1}+\left|\Delta P_{R B}\right|^{n-1}
\end{aligned}
$$

where for the g-functions we take absolute values again at the end to insure positive values. (We note in passing that these functions can be undefined when quantities inside absolute value signs are equal to zero. This will be dealt with below.) Substituting into Equations 21 and 22, we obtain:

$$
\begin{aligned}
e r r Q_{s} & =\left[\left(\frac{R K n f}{2(R-S)}\right)^{2}\left(e r r \Delta P_{\text {on }}\right)^{2}+\left(\frac{K n g_{R}}{(R-S)}\right)^{2}\left(e r r \Delta P_{\text {off }}\right)^{2}+\left(\frac{K n h}{2(R-S)}\right)^{2}\left(e r r \Delta P_{R B}\right)^{2}\right. \\
& \left.+\left(\frac{Q_{r}}{(R-S)}\right)^{2}(e r r R)^{2}+\left(\frac{Q_{s}}{(R-S)}\right)^{2}(e r r S)^{2}+\left(\frac{Q_{s}}{K}\right)^{2}(e r r K)^{2}\right]^{1 / 2}
\end{aligned}
$$

and 


$$
\begin{aligned}
e r r Q_{r}= & {\left[\left(\frac{S K n f}{2(R-S)}\right)^{2}\left(e r r \Delta P_{o n}\right)^{2}+\left(\frac{K n g_{S}}{(R-S)}\right)^{2}\left(e r r \Delta P_{o f f}\right)^{2}+\left(\frac{K n h}{2(R-S)}\right)^{2}\left(e r r \Delta P_{R B}\right)^{2}\right.} \\
& \left.+\left(\frac{Q_{r}}{(R-S)}\right)^{2}(e r r R)^{2}+\left(\frac{Q_{s}}{(R-S)}\right)^{2}(e r r S)^{2}+\left(\frac{Q_{r}}{K}\right)^{2}(e r r K)^{2}\right]^{1 / 2}
\end{aligned}
$$

\section{Pathological Behavior of the Functions $f, g$, and $h$}

Examination of the functions $f, g_{R}, g_{s}$, and $h$ shows that they can behave pathologically under certain conditions. "Pathological behavior" in this case refers to the fact that the functions have singularities, or values of the independent variables for which one or more denominators go to zero, causing the function to be undefined. In the vicinity of these singularities, the function takes on very large values, with large variation within a small range of an independent variable. Such behavior can make them unreliable indicators of the errors they are used to calculate in Equations 24 and 25.

The critical question is this. How large is the range of values of a given independent variable for which this unwanted behavior occurs? For example, a range of plausible values for $\Delta \mathrm{P}_{\text {on }}$ is perhaps from -5 to $+5 \mathrm{~Pa}$. If the subset of values of $\Delta \mathrm{P}_{\text {on }}$ for which the function $f$ is rapidly varying is a large fraction of this range, then Equations 24 and 25 may not be very useful. But if the pathological range is very limited, say to a few tenths of a pascal, and if, moreover, there is a reasonable "fix" that can be implemented within this range, then the difficulty is more apparent than real.

This subject is discussed further in Appendix 1. There it is argued that as a reasonable rule of thumb, these functions can be used as calculated unless they return a value greater than 4 or are undefined. This will seldom happen, but in such cases a maximum value of 4 is to be used.

\section{A Criterion of Allowable Error}

We will now do a baseline assessment of the relative sizes of errors in each of the independent variables that would be acceptable in practice. To accomplish this, we will use Equations 24 and 25, and ask what sizes of these errors would produce a specified error in $Q_{s}$ and $Q_{r}$, if the factor under study were the only source of error. The allowed error in $Q_{S}$ or $Q_{r}$ caused by errors in one of the independent variables will be set small enough that the error in $Q_{s}$ or $Q_{r}$ caused by errors in all the independent variables will fall within the agreed-upon criterion, under the baseline assumption that all the independent variables contribute equally to this error.

Before we can estimate the allowable error in each of the independent variables $\left(\Delta \mathrm{P}_{\text {on }}, \Delta \mathrm{P}_{\text {off }}\right.$, $\Delta \mathrm{P}_{\mathrm{RB}}, \mathrm{R}, \mathrm{S}$, and $\mathrm{K}$ ), we need a reasonable criterion for selecting the allowable error in leakage rate $\left(Q_{s}\right.$ or $\left.Q_{5}\right)$. Although the selection of such a criterion is open to discussion, it would appear evident 
that we could tolerate a larger error in the duct leakage if the leakage is very large than if it is small. For example, a measurement error of $100 \mathrm{cfm}$ in a $400 \mathrm{cfm}$ leakage will place it between 300 and 500 $\mathrm{cfm}$. For a typical residence, any supply or return duct leakage within this range is probably going to be large enough to warrant repair. However, a measurement error of $100 \mathrm{cfm}$ in a $100 \mathrm{cfm}$ leakage will leave us uncertain whether the duct leaks at the rate of $200 \mathrm{cfm}$ or is air-tight.

In the light of this example, let us see what happens under either of two obvious scenarios. Suppose we specify a maximum allowed error as a percentage of the leakage (say 25\%), and suppose further that we then specify the maximum error that any one independent variable can contribute as about $40 \%$ of this, or $10 \%$. We trust the quadrature law to give us an average allowed error involving our 6 independent variables as $\sqrt{ } 6$ times the allowed error in any one variable-- $\sqrt{ } 6$ times $10 \%$ is very nearly $25 \%$. For large leakage rates this would seem a reasonable choice, but suppose the leakage is very small, say $40 \mathrm{cfm}$. Should we demand that the error on this leakage caused by an error in any independent variable be only $4 \mathrm{cfm}$ ? Do we really need $10 \mathrm{cfm}$ overall accuracy in this case? The answer is almost surely no. If the fan-flow rate is a typical 800 to $1400 \mathrm{cfm}$, we should be quite happy if we could determine that supply or return leakage is $40 \pm 40 \mathrm{~cm}$, because it would probably not be worth going to great lengths to find and fix such a small leakage.

This discussion would seem to lead to a compromise of the following sort. Specify a maximum percentage error in supply or return leakage that is acceptable, but establish a minimum absolute value of leakage error which will always be acceptable, even if the measured leakage itself is small enough that use of this value will result in a large percentage error. Then divide these limits by $\sqrt{ } 6$ (approximately 2.5 ) to obtain the allowed leakage stemming from any one independent variable, and depend on the addition of errors in quadrature to bring the total error back up to 2.5 times (rather than six times) as great.

It is recognized that this may be somewhat confusing, so let us go through a numerical example which contains numbers the author considers to be reasonable. For large leakage rates, let us establish a $25 \%$ error as the maximum allowable. This would mean that we have determined, say, a $400 \mathrm{cfm}$ leakage rate to within $100 \mathrm{cfm}$ of the true value. This is probably good enough for decision-making purposes. For low leakage rates, let us make the judgment that knowing the leakage to within $\pm 50 \mathrm{cfm}$ will always be good enough. We then divide these criteria by $\sqrt{ } 6$ or -2.5 when looking at the effect of errors in any one independent variable, so we demand now that the error in supply or return leakage caused by error in any independent variable be no greater than $10 \%$ of the measured leakage or $20 \mathrm{~cm}$, whichever is greater.

With this criterion settled upon, we can now proceed. By setting all the independent-variable errors but one in Equations 24 and 25 to zero in turn and evaluating the resulting error in the remaining independent variable, we obtain the following equations. For $Q_{8}$ : 


$$
\begin{aligned}
\text { err } Q_{s-\text { allowed }} & =\frac{R K n f}{2(R-S)} \operatorname{err} \Delta P_{\text {on-allowed }} \\
e r r Q_{s-\text { allowed }} & =\frac{K n g_{R}}{(R-S)} \operatorname{err} \Delta P_{\text {off-allowed }} \\
\text { err } Q_{s-\text { allowed }} & =\frac{K n h}{2(R-S)} \operatorname{err} \Delta P_{R B \text {-allowed }} \\
\text { err } Q_{s-\text { allowed }} & =\frac{Q_{r}}{(R-S)} e r r R_{\text {allowed }} \\
\text { err } Q_{s-\text { allowed }} & =\frac{Q_{s}}{(R-S)} \text { err } S_{\text {allowed }} \\
\text { err } Q_{s-\text { allowed }} & =\frac{Q_{s}}{K} \text { errK allowed }
\end{aligned}
$$

and for $Q_{r}$ :

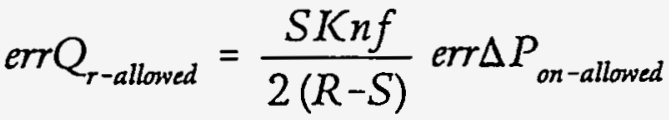

$$
\begin{aligned}
& \text { err } Q_{r-\text { allowed }}=\frac{K n g_{S}}{(R-S)} \operatorname{err} \Delta P_{\text {off-allowed }} \\
& \text { err } Q_{r-\text { allowed }}=\frac{K n h}{2(R-S)} \operatorname{err} \Delta P_{R B \text {-allowed }} \\
& \text { err } Q_{r \text {-allowed }}=\frac{Q_{r}}{(R-S)} \text { err } R_{\text {allowed }} \\
& \text { err } Q_{r \text {-allowed }}=\frac{Q_{s}}{(R-S)} \text { errS } S_{\text {allowed }} \\
& \text { err } Q_{r \text {-allowed }}=\frac{Q_{r}}{K} \text { err } K_{\text {allowed }}
\end{aligned}
$$


These equations may be solved for the allowed errors in the independent variables, taking care to use the minimum of the two values so obtained:

$$
\begin{aligned}
e r r \Delta P_{\text {on-allowed }} & =\frac{2(R-S)}{K n f} \min \left\{e r r Q_{s-a l l o w e d} / R, e r r Q_{r-a l l o w e d} / S\right\} \\
e r r \Delta P_{\text {off-allowed }} & =\frac{(R-S)}{K n} \min \left\{e r r Q_{s-\text { allowed }} / g_{R}, e r r Q_{r-\text { allowed }} / g_{S}\right\} \\
e r r \Delta P_{R B \text {-allowed }} & =\frac{2(R-S)}{K n h} \min \left\{e r r Q_{s-a l l o w e d}, e r r Q_{r-\text { allowed }}\right\} \\
e r r R_{\text {allowed }} & =\frac{(R-S)}{\left|Q_{r}\right|} \min \left\{e r r Q_{s-\text { allowed }}, e r r Q_{r-\text { allowed }}\right\} \\
e r r S_{\text {allowed }} & =\frac{(R-S)}{\left|Q_{s}\right|} \min \left\{e r r Q_{s-\text { allowed }}, e r r Q_{r-\text { allowed }}\right\} \\
\text { errK } K_{\text {allowed }} & =K \min \left\{e r r Q_{s-\text { allowed }} /\left|Q_{s}\right|, e r r Q_{r-\text { allowed }} /\left|Q_{r}\right|\right\}
\end{aligned}
$$

The absolute value sign around $\mathrm{Q}_{s}$ would normally not be needed since it is almost always a positive number. (The possibility of negative supply leakage being caused by the static pressure going negative immediately behind the registers has been suggested.)

We should note here that all of the allowed errors, except that for K, are proportional to R-S. It therefore behooves us to make R-S as large as possible. By blocking off the return register more severely, $\mathrm{R}$ can be made to increase and $\mathrm{S}$ to decrease, because the return duct becomes more depressurized than with the register unblocked, while the supply duct becomes less pressurized. The proposed test method specifies that the return register be blocked until the pressure inside the return duct is 100 pascals. (Anything more, it is feared, might damage the system.) Under these conditions, $\mathrm{R}$ typically has a value between 1.4 and 1.8 , while $\mathrm{S}$ is typically between 0.7 and 0.9 . $\mathrm{R}$ will be taken typically to equal $1.6, \mathrm{~S}$ to equal 0.8 , and $\mathrm{R}-\mathrm{S}$ to equal 0.8 . We will use these values to benchmark the allowed errors in the discussion below.

\section{Allowable Errors in the Six Independent Variables}

Let us now look at each of the independent variables in Equation 28 in the light of this criterion.

Allowable Errors in K. Observing the sixth line of Equations 28, we note that the allowed fractional error in $\mathrm{K}$ (i.e. errK $\mathrm{allowed}_{\mathrm{K}} / \mathrm{K}$ ) is the minimum allowed fractional error in $\mathrm{Q}_{\mathrm{s}}$ or $\mathrm{Q}_{r}$. By the 
criterion we have just developed, the allowed fractional errors in $\mathrm{Q}_{\mathrm{s}}$ and $\mathrm{Q}_{\mathrm{r}}$ are never less than $10 \%$, but may be more if the leakage in question is less than $200 \mathrm{cfm}$. Since neither fractional error is less than $10 \%$, their minimum is never less than $10 \%$, and so we will be safe to say that it is good enough to measure $\mathrm{K}$ to within $10 \%$. In cases where both supply and return leakage are small, the allowed error in $\mathrm{K}$ will be greater than $10 \%$, but usually one or another of the ducts will leak more than 200 cfm, and so we will not lose much by establishing a blanket $10 \%$ measurement accuracy requirement on $\mathrm{K}$ (or on any other quantity, such as CFM50, from which $\mathrm{K}$ is derived).

Allowable Errors in S. We consider separately the cases where the return leakage is greater than or less than the supply leakage.

Return-Leak-Dominated Systems. In these systems $\left|Q_{r}\right|>\left|Q_{s}\right|$, and therefore the allowed error in $Q_{s}$ must be less than or equal to that for $Q_{r}$. The fifth line of Equations 28 then tells us that the allowed error in $\mathrm{S}$ is equal to $\mathrm{R}-\mathrm{S}$ multiplied by the allowed fractional error in $\mathrm{Q}_{\mathrm{s}}$, which is never less than $10 \%$. Using the typical value of 0.8 for $\mathrm{R}-\mathrm{S}$, we conclude that the allowed error in $\mathrm{S}$ for return-leak-dominated systems will be at least 0.08 .

Supply-Leak-Dominated Systems. In these systems $\mathrm{Q}_{\mathrm{r}}$ provides the minimum allowable error, and the fifth line of Equations 28 reads

$$
\text { errS } S_{\text {allowed }}=(R-S) \frac{e r r Q_{r-\text { allowed }}}{\left|Q_{s}\right|}
$$

and the clamp on errors in $\mathrm{S}$ is likely to be more severe. But we can get a practical lower limit on this clamp by noting that the minimum allowed error on $Q_{r}$ is $20 \mathrm{cfm}$ while in most residential systems supply leakage is unlikely to exceed about $400 \mathrm{~cm}$. Again using 0.8 as a value for R-S, the above equation yields an allowed error in $\mathrm{S}$ of 0.04 .

Preliminary measurements indicate that $\mathrm{S}$ is easier to measure than $\mathrm{R}$. In one series of tests conducted by one individual $S$ varied by less than 0.02 . In another series conducted by five different testers, it varied by 0.09 ( 0.05 if one outlier was eliminated). It is hoped that more comprehensive testing may enable the measurement of $S$ to be fixed within a limit of 0.04 , for example by specifying that the supply register to be used should be one that is in best communication with the main part of the supply duct system.

Allowable Errors in R. In the same fashion as above, we consider supply-leak and return-leak dominated systems separately.

Supply-Leak-Dominated Systems. As the fourth line of Equations 28 indicates, in supplyleak-dominated systems the allowed error in $\mathrm{R}$ is equal to R-S multiplied by the allowed fractional error in $Q_{r}$ For systems in which supply and return leaks are both larger than $200 \mathrm{~cm}$, this will result 
in an allowed error in $\mathrm{R}$ of $0.8 \times 0.1$, or 0.08 . For systems where the supply leaks are large but return leaks are small, the allowed error in $\mathrm{R}$ will be larger than this. For example, in a system with measured return leakage of $50 \mathrm{cfm}$, the allowed fractional return leakage error is $20 / 50$ or 0.4 , allowing therefore an error in $\mathrm{R}$ of 0.28 .

Return-Leak-Dominated Systems. In these systems, $|\mathrm{Q} s|$ is less than $|\mathrm{Qr}|$, and hence the fourth line of Equations 28 yields

$$
e r r R_{\text {allowed }}=(R-S) \frac{e r r Q_{s-a l l o w e d}}{\left|Q_{r}\right|}
$$

In systems where return leaks dominate, the limitations on errors in $R$ can be severe, as shown in the following example. Suppose $Q_{s}<200 \mathrm{cfm}$, so err $Q_{\text {sallowed }}=20 \mathrm{cfm}$. Suppose also that $Q_{r}$ is high, say $400 \mathrm{cfm}$. In this case the allowed error in R will be $0.8 \times 20 / 400$ or 0.04 . At first sight, this seems to be a mirror image of the situation with $S$. Unfortunately, $R$ has been found to be much more subject to variability than $S$. In the series of tests by one individual mentioned above, the measured values of $R$ had a range of nearly 0.5 , although some of these measurements were made at points in the duct outside the limits specified by the standard. In the series conducted by five different individuals, in which the attempt was made to follow the standard, the values of $R$ had a range of 0.3 ( 0.16 if one outlier is eliminated). The house used in the second series had five return registers, which complicated the determination of where in the return duct the measurement should be made. These examples, though preliminary, indicate that the measurement procedure for $\mathrm{R}$ needs to be specified with care in the standard, particularly for systems with more than one return register.

A rule of thumb for the allowed error in $\mathrm{R}$ for return-leak dominated systems can be generated by using R-S $=0.8$ and the minimum allowed error in $Q_{s}= \pm 20 \mathrm{cfm}$. (Since the system is return-leakdominated, the supply leakage is likely to be less than $200 \mathrm{cfm}$.) This gives the simple relation err $R_{\text {allowed }}=16 /\left|\mathrm{Q}_{\mathrm{r}}\right|$.

Allowable Errors in $\Delta \mathrm{P}_{\mathrm{RB}}$. The first thing we need to note, on examining the third line of Equations 28, is that the allowable error in $\Delta \mathrm{P}_{\mathrm{RB}}$ is dependent on $\mathrm{K}$. This is in contrast to the allowable errors in $\mathrm{R}$ and $\mathrm{S}$, which do not depend on $\mathrm{K}$. Since $\mathrm{K}$ is in the denominator of the expression in Equations 28, it means that the allowed error in $\Delta \mathrm{P}_{\mathrm{RB}}$ will be less in a leaky house than in a tight one. This is reasonable, in that the house pressure test uses the house as a standard of comparison. If the house were very leaky (e.g. the windows were open) the house pressure would not change at all when the fan came on. So let us establish two houses, a leaky house and a tight house, defined by their blower-door leakage tests as CFM50. The leaky house will be defined to have CFM50 $=4000$, while the tight house will have $C F M 50=2000$. The $\mathrm{K}$ values are defined as either $\mathrm{cfm} / \mathrm{Pa}^{0.65}(\mathrm{IP})$ or $\mathrm{m}^{3} / \mathrm{s}-\mathrm{Pa}^{0.65}$ (SI), so to obtain the $\mathrm{IP}$ value of $\mathrm{K}$ one needs to divide by $50^{0.65}$ or 12.72 , while the SI value is obtained by first converting $\mathrm{cfm}$ to $\mathrm{m}^{3} / \mathrm{s}$ and then dividing by $50^{0.65}$, for an overall conversion factor of $3.71 \times 10^{-5}$. Thus the $\mathrm{K}$ values for the tight and leaky houses we have chosen will be 157 and $314 \mathrm{cfm} / \mathrm{Pa}^{0.65}$ or 0.074 and $0.148 \mathrm{~m}^{3} / \mathrm{s}-\mathrm{Pa}^{0.65}$. 
We will use the benchmark $20 \mathrm{cfm}$ allowed error in either $\mathrm{Q}_{r}$ or $\mathrm{Q}_{\mathrm{s}}$, assuming that at least one of these quantities will usually be less than $200 \mathrm{cfm}$. Then using the typical value of $0.8 \mathrm{for} R-\mathrm{S}$, and $\mathrm{n}=0.65$, we obtain the following expression for the allowed error in $\Delta \mathrm{P}_{\mathrm{RB}}$ :

$$
\operatorname{err} \Delta P_{R B \text {-allowed }}=0.3 / \mathrm{h}
$$

for the tight house and half this value for the leaky house. (Note that the numerical coefficients are the same regardless of whether flows were measured in $\mathrm{cfm}$ or in $\mathrm{m}^{3} / \mathrm{s}$, as long as pressures are in pascals.)

To determine the allowed error in any particular case, it is possible to evaluate the $h$-function and compute. For an understanding of the magnitudes of error that would in general be allowed, it is necessary to investigate the behavior of this function for reasonable values of its variables.

Figure A-1 in the Appendix shows the behavior of the f-function, as a function of $\Delta \mathrm{P}_{\text {off }}$, with $\Delta \mathrm{P}_{\text {on }}$ as a parameter. The discussion of the $h$-function in the Appendix shows that this same chart can be used to visualize the behavior of $h$, if $\Delta \mathrm{P}_{\mathrm{RB}}$ is substituted for $\Delta \mathrm{P}_{\text {on }}$ as the parameter.

The $h$-function, then, can take on quite a range of values, from a little more than 1 up to the practical upper limit of about 4 , as discussed in the Appendix. To get a slightly more detailed perspective, we should note that $\Delta \mathrm{P}_{\mathrm{RB}}$ is usually a decidedly positive number, seldom close to zero, because blocking the return biases the system strongly in the direction of larger return leakage, which tends to pressurize the house. The only exception is the circumstance where supply leakage dominates sufficiently that blocking the return still does not bring the return leakage up to the level of that in the supply. As for $\Delta \mathrm{P}_{\text {off }}$, it, too, is likely to be positive because of stack effect, unless the test is performed on a hot summer day. So we should look at the right-hand half of Figure 1, and note two main kinds of cases: first, where we are not close to a singularity, in which case $h$ is likely to be between 1 and 2 , and second, where we are close to a singularity, in which case $h$ is likely to be between 2 and 4 . The first case is by far the more probable. So we will take 1.5 as a representative value of $h$, and therefore the allowed error in $\Delta \mathrm{P}_{\mathrm{RB}}$ will be approximately 0.2 pascals for the tight house and 0.1 pascals for the leaky house. But we will add the caveat that the allowed error is likely to be less when $\Delta \mathrm{P}_{\mathrm{RB}}$ is within $0.5 \mathrm{~Pa}$ of either zero or $2 \Delta \mathrm{P}_{\text {off. }}$.

Allowable Errors in $\Delta \mathrm{P}_{\text {on }}$. The first line of Equations 28 is similar to the third line except for two things: the function $h$ is replaced by the function $f$, and that the allowed errors in $Q_{s}$ and $Q_{r}$ are divided by $\mathrm{R}$ and $\mathrm{S}$, respectively.

The fact that $\mathrm{R}$ and $\mathrm{S}$ are involved in the min function requires us to look at it somewhat differently than in the previous case: 
- If $\mathrm{Q}_{\mathrm{s}}<200 \mathrm{cfm}$, then the first term in the min function ( $\mathrm{err}_{\mathrm{s}-\mathrm{allowed}} / \mathrm{R}$ )is certainly less than the second term (errQ $\mathrm{rallowed}_{\text {( }} / \mathrm{S}$ ), and for the typical $\mathrm{R}=1.6$ the min function equals $12.5 \mathrm{cfm}$.

- If Qs is between 200 and $400 \mathrm{cfm}$, the first term controls (for typical $\mathrm{R}$ and $\mathrm{S}$ values of 1.6 and 0.8 ) and the min function will ramp from 12.5 to $25 \mathrm{cfm}$ as Qs goes from 200 to $400 \mathrm{cfm}$.

- If $\mathrm{Q}_{\mathrm{s}}>400 \mathrm{cfm}$, we can benchmark the min function by saying that if $\mathrm{Q}_{\mathrm{r}}$ is less than $200 \mathrm{cfm}$, the second term controls and for the typical $S=0.8$ the min function has a value of $25 \mathrm{cfm}$. If both leakages are large this procedure will underestimate the allowed error in $\Delta P_{\text {on }}$, so this provides a lower limit on the allowed error, i.e., the allowed error could be greater and so using $25 \mathrm{cfm}$ as the output of the min function is conservative.. following:

Using then the typical values $R=1.6$ and $S=0.8$, for the tight house this reduces to the

$$
\begin{aligned}
\text { err } \Delta P_{\text {on-allowed }}= & 0.2 / f \quad \text { if } Q_{s}<200 \mathrm{cfm} \\
& \frac{Q_{s}}{1000 f} \quad \text { if } 200<Q_{s}<400 \\
& 0.4 / f \quad \text { if } Q_{s}>400 \mathrm{cfm}
\end{aligned}
$$

The behavior of the f-function can be seen in Figure A-1, in the Appendix, where the parameters are now those actually shown on the chart. (Note that for negative values of $\Delta \mathrm{P}_{\text {on }}$, the graphs will look the same except that they are reflected about the vertical axis $\Delta \mathrm{P}_{\text {off }}=0$, i.e. a mirror reflection.) The main difference between this case and that of $\Delta \mathrm{P}_{\mathrm{RB}}$ is that we are somewhat more likely to be in the vicinity of a singularity, since $\Delta \mathrm{P}_{\text {on }}$ is not skewed to the right as $\Delta \mathrm{P}_{\mathrm{RB}}$ is. In particular we are more likely to be near $\Delta \mathrm{P}_{\text {on }}=0$ than to $\Delta \mathrm{P}_{\mathrm{RB}}=0$, so the general trend of values for the $f$-function (over the range of $\Delta \mathrm{P}_{\text {off }}$ values) is likely to be somewhat higher than the trend of values for the $h$-function (over the same range of $\Delta P_{\text {off }}$ values). So typical values of $f$ will be somewhat higher than the typical values of $h$ in the preceding case. We will therefore take 2.0 as the typical value of $f$, with the same caveat about watching for singularities. The resulting formula for the allowed error in $\Delta \mathrm{P}_{\text {on }}$ is then:

$$
\begin{aligned}
\text { err } \Delta P_{\text {on-allowed }}= & 0.1 \quad \text { if } Q_{s}<200 \mathrm{cfm} \\
& \frac{Q_{s}}{2000} \quad \text { if } 200<Q_{s}<400 \\
& 0.2 \quad \text { if } Q_{s}>400 \mathrm{cfm}
\end{aligned}
$$

for the tight house and half these values for the leaky house. 
Allowable Errors in $\Delta \mathrm{P}_{\text {off }}$. The second line of Equations 28 is similar to the first and third, except that the function $\mathrm{g}$, which replaces $\mathrm{f}$ or $\mathrm{h}$ in this equation, has two forms, $\mathrm{g}_{\mathrm{R}}$ and $\mathrm{g}_{\mathrm{s}}$. These differ on which coefficient, $\mathrm{R}$ or $\mathrm{S}$, appears in the second term of the definition (Equations 23). Figures A-3 and A-4 in the Appendix show some values of this function for the case $\Delta \mathrm{P}_{\text {on }}=-1$. The behavior shown is typical of these functions. Because they are the absolute values of the differences of two absolute values that often tend to cancel, these functions are usually considerably less than 1 , except near their singularities, which in the case of the g-functions occur at $\Delta \mathrm{P}_{\mathrm{on}}=2 \Delta \mathrm{P}_{\text {off }}$ and $\Delta \mathrm{P}_{\mathrm{RB}}$ $=2 \Delta \mathrm{P}_{\text {off. }}$. We will benchmark the allowed error by saying that the larger of these two functions (usually $\mathrm{g}_{\mathrm{R}}$ ) is typically about 0.5 (except near singularities) and the the associated allowed error in its associated $\mathrm{Q}$ (usually $\mathrm{Q}_{\text {s-allowed }}$ is $20 \mathrm{cfm}$, making the output of the min function in this case equal to $20 / 0.5$ or 40 . This results in an allowed error in $\Delta \mathrm{P}_{\text {off }}$, for the tight house, of [0.8/(157 X 0.65)] $\mathrm{X} 40$ or $0.32 \mathrm{~Pa}$. For the leaky house the allowed error would be half this large. It should be noted, however, that there is more variability here than in the case of $\Delta \mathrm{P}_{\text {on }}$ and $\Delta \mathrm{P}_{\mathrm{RB}}$ because not only do the g-functions have singularities (like $f$ and $h$ ) but they also can take on quite low values (even zero) in certain specific cases. This means that the actual allowed error in $\Delta \mathrm{P}_{\text {off }}$ can be considerably more or less than the above values, but they still represent reasonable benchmark values.

\section{Summary}

For each of the six active independent variables $\left(\mathrm{K}, \Delta \mathrm{P}_{\text {on, }}, \Delta \mathrm{P}_{\text {off }}, \Delta \mathrm{P}_{\mathrm{RB}}, \mathrm{R}\right.$, and $\left.\mathrm{S}\right)$, Table 1 presents the allowable errors resulting from this criterion. (Note that $\mathrm{K}$ is called $\mathrm{C}_{\text {env }}$ in Standard 152P.) The likely points of difficulty are pointed out in the table. One is the value of $\mathrm{R}$ in return-leak dominated systems. This analysis calls for a precision in the area of 0.03 to 0.04 , while preliminary experiments indicate that the measured value of $R$ may show considerably more variation than this unless the measurement procedure is very carefully specified. This means that the value of supply leakage can be quite questionable in return-leak dominated systems. The value of $S$ appears to be easier to characterize, and should be measurable to within the stated error maximums.

The allowed errors in the pressure differences are generally smallest for $\Delta \mathrm{P}_{\mathrm{on}}$, next smallest for $\Delta \mathrm{P}_{\mathrm{RB}}$, and least restrictive for $\Delta \mathrm{P}_{\text {off }}$, except when these variables are such that a singularity is approached in one or more of the functions $f, g$, and $h$.

The other point of difficulty is in leaky houses. Since the house serves as the pressure standard, if the house is very leaky its usefulness in this role diminishes. The extreme case would be if one tried to do the house pressure test with the windows open, in which case the observed houseattic pressure differences would all be the same and the results would be meaningless.

On the other side of the coin, there are situations where the allowed errors in some of the quantities are large. The flow coefficient, for example, should be measurable to within $10 \%$ using a blower door. Also, it is likely that $S$ can be measured reliably to within \pm 0.02 , so the restrictions on errors in this quantity are likely to be met. When the return leakage is small, the value of $\mathrm{R}$ does not have to be known with any great precision. Finally, the limits on the errors developed here are based on the requirement that the errors on both $Q_{r}$ and $Q_{s}$ must be kept within defined bounds. 
Table 1. Allowed Errors in Independent Variables of House Pressure Test for Duct Leakage

\begin{tabular}{|c|c|c|c|}
\hline \multirow{2}{*}{$\begin{array}{l}\text { Independent } \\
\text { Variable }\end{array}$} & \multicolumn{2}{|c|}{ Allowable Error } & \multirow{2}{*}{$\begin{array}{l}\text { Difficulty in meeting } \\
\text { error criterion }\end{array}$} \\
\hline & $\begin{array}{l}\text { Systems with Supply } \\
\text { Leakage Dominant }\end{array}$ & $\begin{array}{l}\text { Systems with Return } \\
\text { Leakage Dominant }\end{array}$ & \\
\hline $\begin{array}{l}\mathrm{K} \text {, the envelope } \\
\text { flow coefficient }\end{array}$ & \multicolumn{2}{|c|}{$10 \%$, independent of which leakage is dominant. } & $\begin{array}{l}\text { Should be easy to } \\
\text { meet. }\end{array}$ \\
\hline $\begin{array}{l}\Delta \mathbf{P}_{\text {on }} \text {, the house- } \\
\text { attic pressure } \\
\text { difference with the } \\
\text { furnace fan on }\end{array}$ & \multicolumn{2}{|c|}{$\begin{array}{l}\text { Allowed error depends on envelope air tightness } \\
\text { but not on dominant leakage. } \\
\text { Tight house: err } \Delta \mathrm{P}_{\text {on-allowed }} \pm 0.1 \text { to } 0.2 \mathrm{~Pa} \\
\text { Leaky house: err } \Delta \mathrm{P}_{\text {on-allowed }} \pm 0.05 \text { to } 0.1 \mathrm{~Pa} \\
\text { (Less if } \Delta \mathrm{P}_{\text {c.. }} \text { is within } 0.5 \mathrm{~Pa} \text { of } \Delta \mathrm{P}_{\text {orf }} \text { or zero) }\end{array}$} & $\begin{array}{l}\text { Hardest to meet in } \\
\text { leaky houses, if } \mathrm{Q}_{s} \text { is } \\
\text { low, or when } \Delta \mathrm{P}_{\mathrm{on}} \text { is } \\
\text { near a singularity in } \\
\text { the f-function. }\end{array}$ \\
\hline $\begin{array}{l}\Delta \mathrm{P}_{\text {off, }} \text { the house- } \\
\text { attic pressure } \\
\text { difference with the } \\
\text { furnace fan off }\end{array}$ & \multicolumn{2}{|c|}{$\begin{array}{l}\text { Allowed error depends on envelope air tightness } \\
\text { and supply duct leakage. } \\
\text { Tight house: err } \Delta \mathrm{P}_{\text {off-2llowed }} \approx \pm 0.32 \mathrm{~Pa} \\
\Delta \mathrm{P}_{\text {off }} \text { Leaky house: err } \Delta \mathrm{P}_{\text {off-allowed }} \approx \pm 0.16 \mathrm{~Pa} \\
\left(\text { Less if } \Delta \mathrm{P}_{\text {orf }} \text { is within } 0.5 \mathrm{~Pa} \text { of } \Delta \mathrm{P}_{\text {o. }} \text { or } \Delta \mathrm{P}_{\mathrm{RB}}\right)\end{array}$} & $\begin{array}{l}\text { Hardest to meet in } \\
\text { leaky houses or if } \\
\Delta P_{\text {off }} \text { is near a sing- } \\
\text { ularity in } g_{R} \text { or } \\
g_{s} \cdot \Delta P_{\text {off }}\end{array}$ \\
\hline $\begin{array}{l}\Delta P_{\mathrm{RB}} \text {, the house- } \\
\text { attic pressure } \\
\text { difference with the } \\
\text { furnace fan on and } \\
\text { the return blocked }\end{array}$ & \multicolumn{2}{|c|}{$\begin{array}{l}\text { Allowed error depends on envelope air } \\
\text { tightness. } \\
\text { Tight house: err } \Delta \mathrm{P}_{\mathrm{RB}-2 \mathrm{Il} \text { owed }} \text { is } \pm 0.2 \mathrm{~Pa} \\
\text { Leaky house: err } \Delta \mathrm{P}_{\mathrm{RB}-2 \mathrm{ll} l \text { wed }} \pm 0.1 \mathrm{~Pa} \\
\text { (Less if } \Delta \mathrm{P}_{\mathrm{RB}} \text { is within } 0.5 \mathrm{~Pa} \text { of } 2 \Delta \mathrm{P}_{\text {off }} \text { or zero) }\end{array}$} & $\begin{array}{l}\text { Hardest to meet in } \\
\text { leaky houses or } \\
\text { when } \Delta \mathrm{P}_{\mathrm{RB}} \text { is near a } \\
\text { singularity in the h- } \\
\text { function. }\end{array}$ \\
\hline $\begin{array}{l}\mathrm{R} \text {, the ratio of } \\
\text { return-duct } \\
\text { pressure with return } \\
\text { blocked to return- } \\
\text { duct pressure with } \\
\text { return unblocked, } \\
\text { to the } 0.6 \text { power }\end{array}$ & $\begin{array}{l} \pm 0.07 \text { for }\left|Q_{r}\right|>200 \mathrm{cfm} \\
\pm 0.14 \text { for }\left|Q_{r}\right| \approx 100 \mathrm{cfm} \\
\pm 0.28 \text { for }\left|Q_{r}\right| \approx 50 \mathrm{cfm}\end{array}$ & $\begin{array}{l} \pm 0.04 \text { if }\left|Q_{r}\right|=400 \mathrm{cfm} \\
\pm 0.08 \text { if }\left|Q_{r}\right|=200 \mathrm{cfm} \\
\pm 0.16 \text { if }\left|Q_{r}\right|=100 \mathrm{cfm}\end{array}$ & $\begin{array}{l}\text { Hardest to meet } \\
\text { when return leakage } \\
\text { is large; then } \\
\text { uncertainty in } Q_{3} \\
\text { tends to balloon. }\end{array}$ \\
\hline $\begin{array}{l}\text { S, the ratio of } \\
\text { supply-duct } \\
\text { pressure with return } \\
\text { blocked to supply- } \\
\text { duct pressure with } \\
\text { return unblocked, } \\
\text { to the } 0.6 \text { power }\end{array}$ & \pm 0.04 & \pm 0.08 & $\begin{array}{l}\text { Should be relatively } \\
\text { easy to meet. }\end{array}$ \\
\hline
\end{tabular}

Note: Tight house defined as CFM50=2000; leaky house defined as CFM50 $=4000$. 
Sometimes it may happen that one of these quantities will be well determined but the other is less well known, which means that the house pressure test will often yield much useful information even when the above criteria are not met. Again, in return-leak dominated systems, it will be common for the return leakage to be known within $25 \%$ but the supply leakage to be in greater doubt, on a percentage basis.

Another plus is that whenever one error is less than the allowed maximum, this permits another allowed maximum to be relaxed. A countervailing negative factor is that the determination of allowable errors has ignored any possible systematic bias in the test method. The extent of such bias, if any, is at present unknown. So it is emphasized at the conclusion of this discussion that these upper limits should be used as relative guidelines, not as absolute requirements.

\section{FAN PRESSURIZATION TEST}

The fan pressurization technique uses a blower door to pressurize the living space to $25 \mathrm{~Pa}$ at the same time that the supply or return ducts are pressurized to the same pressure using a duct blower. (See Figure 2.) A blower door is a calibrated fan installed in a doorway and used to establish a pressure difference between the living space and the outside. The duct blower is a smaller calibrated fan that is used to establish a pressure difference between the inside and the outside of a duct system in which the register openings have been sealed. The blower door is normally used to measure the air leakage flow coefficient of the house envelope. Here it is used to establish the same pressure in the living space that the duct blower established in the ducts. The purpose is to negate any leakage between the duct system and the interior of the house. Any leakage that is measured is therefore assumed to go to the outside. The leakages measured using fan pressurization with duct blower and blower door should, theoretically, be directly comparable to those measured using the house pressure test.

In order to measure leakage rates for the supply and return ducts separately, a temporary air barrier is set in place between the return plenum and the furnace. Leakage to the outside from each of the two duct systems is measured at a standard pressure, which is set at $25 \mathrm{~Pa}$ in Standard 152P. A method of estimating the actual operating pressure in each duct system is given in the standard. The standard relationship between pressure difference and air flow from small leaks is is then used to correct the measured leakage on each side (supply and return) of the duct system to the value appropriate for the actual operating conditions on that side. 


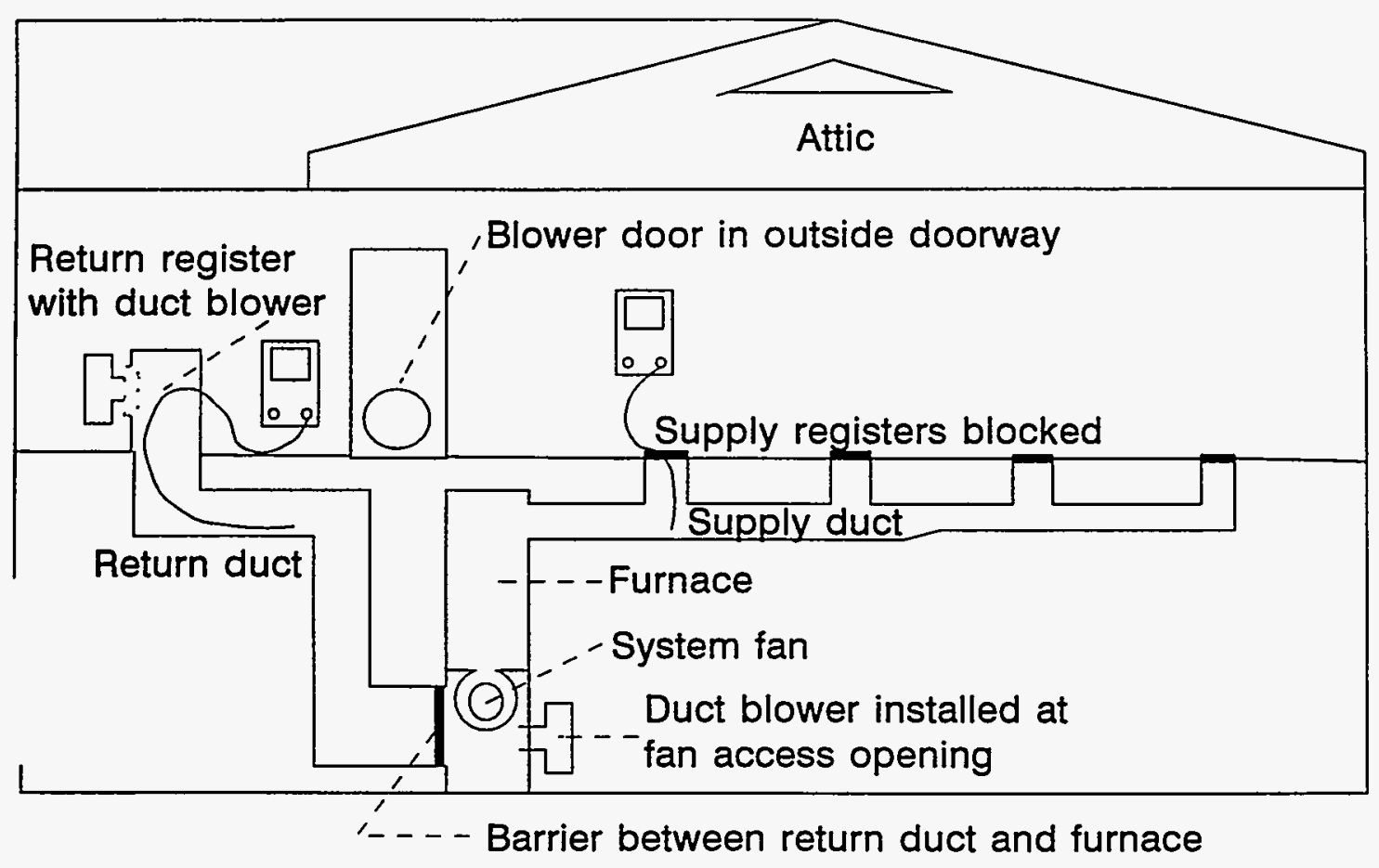

Figure 2. Schematic of the Fan Pressurization Test for Duct Leakage

Supply leakage is usually measured first. The duct blower is attached to one of the openings to the supply duct and all the other openings are sealed. These openings include the registers and the fan access opening in the furnace, which is on the supply side of the return-plenum barrier. The standard allows the tester decide which opening to use as the attachment point for the duct blower, with the proviso that it should be connected to the supply trunk by as short and easy a flow path as possible. A plastic hose is then inserted into one of the (sealed) supply registers, with preference to one that is as near as possible to the supply trunk.

The blower door is now energized and the house pressurized to $25 \mathrm{~Pa}$ with respect to outdoors, and at the same time the duct blower is used to equalize the pressure measured in the supply duct with that in the living space.

It remains to determine the average operating static pressure within the duct system under normal operation. In Standard 152P, this is estimated by averaging pressure-pan readings taken at all the supply registers. A pressure pan is a temporary barrier placed over a register such that no air can pass from that register into the room. A pressure tap in this barrier allows the pressure difference between the still air inside the register and the room air to be measured. The operating supply duct leakage is then set equal to the measured leakage at $25 \mathrm{~Pa}$ multiplied by the 0.6 power of the ratio of the average pressure-pan reading to $25 \mathrm{~Pa}$. (The power 0.6 is used by the standard as the exponent in the flow-pressure relationship for duct leakage.) 
The leakage from the outside into the return duct is measured in a similar manner, except that in this case the duct blower must be attached to a return register, since the fan access opening communicates only with the supply side. To measure the return-duct operating pressure, the pressure pan technique is used unless there are fewer than five return registers, in which case one-half the return plenum pressure is used instead.

\section{Nomenclature}

The following nomenclature will be used. All quantities apply separately to supply and return ducts. That is, for supply ducts, add a subscript $s$ to everything, and for returns add a subscript $r$.

Q Leakage rate to outside from duct in question (may be supply or return)

$\mathrm{Q}_{25} \quad$ Actual leakage to outside @25 $\mathrm{Pa} \Delta \mathrm{P}$ duct with respect to $(\mathrm{w} / \mathrm{r} / \mathrm{t})$ outside

$\mathrm{Q}_{25 \text { in }} \quad$ Actual leakage to inside @ $25 \mathrm{~Pa} \Delta \mathrm{P}$ duct $\mathrm{w} / \mathrm{r} / \mathrm{t}$ inside

$\mathrm{Q}_{25 \text { meas }} \quad$ Measured leakage to outside @25 $\mathrm{Pa} \Delta \mathrm{P}$ duct with respect to (w/r/t) outside

$\Delta \mathrm{P}_{\mathrm{ha}} \quad$ House-ambient pressure difference in pascals under actual measurement conditions (target value $=25 \mathrm{~Pa}$ )

$\Delta \mathrm{P}_{\mathrm{dh}} \quad$ Duct-house pressure difference in pascals under actual measurement conditions (target value $=0$ )

$\mathrm{P} \quad$ Measured duct operating pressure, average of pressure pan readings at each of $n$ registers (or $1 / 2$ the return plenum pressure for return ducts with $<5$ registers)

\section{Relationships Among the Leakages}

The intent of the duct leakage measurement by fan pressurization, using both duct blower and blower door, is to measure $Q_{25}$. Generally, the actual measured quantity $Q$ 25musill differ from this somewhat because of experimental error. A significant part of this error could arise because of leakage to the inside under a slight imbalance between the ducts and the house. Although with careful measurement technique this is normally expected to be small, it is not negligible, and in cases where most of the ductwork is within the conditioned space, it could even become the dominant source of error. so in order to account for all sources of error, we write

$$
Q_{25 \text { meas }}=Q_{25}\left(\frac{\Delta P_{h a}+\Delta P_{d h}}{25}\right)^{0.6}+Q_{25 \text { in }} \operatorname{sign} \Delta P_{d h}\left|\frac{\Delta P_{d h}}{25}\right|^{0.6}
$$

where the first term measures the leakage to the outside and the second term gives leakage to the inside, under the actual test conditions. For the target conditions $\Delta \mathrm{P}_{\mathrm{ha}}=25$ and $\Delta \mathrm{P}_{\mathrm{dh}}=0$, Equation 1 reduces to $Q_{25 \text { meas }}=Q_{25}$.

Under the assumptions embodied in the test method, the duct leakage to the outside under actual operating conditions is equal to 


$$
Q=Q_{25}\left(\frac{P}{25}\right)^{0.6}
$$

Equation 34 can now be solved for $\mathrm{Q}_{25}$ :

$$
Q_{25}=Q_{25 \text { meas }}\left(\frac{25}{\Delta P_{h a}+\Delta P_{d h}}\right)^{0.6}-Q_{25 i n} \frac{\operatorname{sign} \Delta P_{d h}\left|\Delta P_{d h}\right|^{0.6}}{\left(\Delta P_{h a}+\Delta P_{d h}\right)^{0.6}}
$$

Substituting this into Equation 35 yields:

$$
Q=\left(\frac{P}{\Delta P_{h a}+\Delta P_{d h}}\right)^{0.6}\left(Q_{25 \text { meas }}-Q_{2 \sin } \operatorname{sign} \Delta P_{d h}\left|\frac{\Delta P_{d h}}{25}\right|^{0.6}\right)
$$

This is our basic equation for $Q$, on which the error analysis will be based.

The above equations are subject to possible systematic bias, due to a variety of causes that may include the following:

- For the $25 \mathrm{~Pa}$ leakage measurement, the pressure in the duct is assumed to be the same everywhere, but it may in fact vary from place to place because of pressure drops associated with leakage;

- The pressure-pan technique of determining the average operating pressure of the duct system may be biased;

- The leakage may occur preferentially at places where the pressure is higher or lower than the measured pressure;

- The exponent in the pressure-flow relationship may be different from the assumed 0.6 .

As stated in the Introduction, systematic biases are not within the scope of this report, which considers random uncertainty only.

\section{Error Propagation}

The next step will be to take partial derivatives of $Q$ with respect to the independent variables $Q_{25 \text { meas, }}$, $P, \Delta P_{h a}$, and $\Delta P_{d h}$. Since $Q_{25 i n}$ is not measured, we do not take it as one of the independent variables, but instead as a parameter on which the relative importance of the error in $\Delta \mathrm{P}_{\mathrm{dh}}$ will depend. 
One other item of note is that, once the partial derivatives have been taken, it will often be admissible to set $\Delta \mathrm{P}_{\mathrm{ha}}+\Delta \mathrm{P}_{\mathrm{dh}}$ equal to 25 pascals. we may not, of course, do this before taking the derivatives as that would mask some of the variations which it is our purpose to detect.

The partial derivatives, then, are as follows.

For $\mathrm{Q}_{25 \text { meas }}$ :

$$
\begin{aligned}
\frac{\partial Q}{\partial Q_{25 \text { meas }}} & =\left(\frac{P}{\Delta P_{h a}+\Delta P_{d h}}\right)^{0.6} \\
& \approx 0.145 P^{0.6}
\end{aligned}
$$

For $\mathrm{P}$ :

$$
\begin{aligned}
\frac{\partial Q}{\partial P} & =0.6 P^{-0.4}\left(\Delta P_{h a}+\Delta P_{d h}\right)^{-0.6}\left(Q_{25 \text { meas }}-Q_{25 i n} \operatorname{sign} \Delta P_{d h}\left|\frac{\Delta P_{d h}}{25}\right|^{0.6}\right) \\
& \approx 0.0870 P^{-0.4}\left(Q_{25 \text { meas }}-0.145 Q_{25 \text { in }} \operatorname{sign} \Delta P_{d h}\left|\Delta P_{d h}\right|^{0.6}\right)
\end{aligned}
$$

For $\Delta \mathrm{P}_{\mathrm{ha}}$ :

$$
\begin{aligned}
\frac{\partial Q}{\partial \Delta P_{h a}} & =-0.6 P^{0.6}\left(\Delta P_{h a}+\Delta P_{d h}\right)^{-1.6}\left(Q_{25 \text { meas }}-Q_{25 i n} \operatorname{sign} \Delta P_{d h}\left|\frac{\Delta P_{d h}}{25}\right|^{0.6}\right) \\
& \approx-0.00348 P^{0.6}\left(Q_{25 \text { meas }}-0.145 Q_{25 \text { in }} \operatorname{sign} \Delta P_{d h}\left|\Delta P_{d h}\right|^{0.6}\right)
\end{aligned}
$$

The calculation of the partial with respect to $\Delta \mathrm{P}_{\mathrm{dh}}$ is more complicated, as shown in Equation 41 . Here, however, we face a problem. The derivative that remains in the second term is equal to $0.6\left|\Delta \mathrm{P}_{\mathrm{dh}}\right|^{-0.4}$, and we are interested in computing errors for a central value that is at or very near $\Delta \mathrm{P}_{\mathrm{dh}}=0$, precisely the value for which this function is undefined . 


$$
\begin{gathered}
\frac{\partial Q}{\partial \Delta P_{d h}}=\left(\frac{P}{\Delta P_{h a}+\Delta P_{d h}}\right)^{0.6}\left(\frac{-Q_{25 i n}}{25^{0.6}} \frac{d \operatorname{sign} \Delta P_{d h}\left|\Delta P_{d h}\right|^{0.6}}{d \Delta P_{d h}}\right)+ \\
+\left(Q_{25 \text { meas }}-Q_{25 i n} \operatorname{sign} \Delta P_{d h}\left|\frac{\Delta P_{d h}}{25}\right|^{0.6}\right)\left[\frac{-0.6 P^{0.6}}{\left(\Delta P_{h a}+\Delta P_{d h}\right)^{1.6}}\right] \\
=\left[\frac{-0.6 P^{0.6}}{\left(\Delta P_{h a}+\Delta P_{d h}\right)^{1.6}}\right]\left(Q_{25 \text { meas }}+Q_{25 i n} \frac{\left(\Delta P_{h a}+\Delta P_{d h}\right)}{25^{0.6}} \frac{d \operatorname{sign} \Delta P_{d h}\left|\Delta P_{d h}\right|^{0.6}}{d \Delta P_{d h}}\right. \\
\left.\quad-Q_{25 i n} \operatorname{sign} \Delta P_{d h}\left|\frac{\Delta P_{d h}}{25}\right|^{0.6}\right) \\
\approx-0.00348 P^{0.6}\left(Q_{25 \text { meas }}+3.62 Q_{25 i n} \frac{d \operatorname{sign} \Delta P_{d h}\left|\Delta P_{d h}\right|^{0.6}}{d \Delta P_{d h}}\right. \\
\left.-0.145 Q_{25 i n} \operatorname{sign} \Delta P_{d h}\left|\frac{\Delta P_{d h}}{25}\right|^{0.6}\right)
\end{gathered}
$$

Fortunately, there is a way around this problem. The purpose of calculating the derivative is to obtain an estimate of how much the function varies for a given amount of variation in the independent variable. In general, for a monotonically increasing (or decreasing) function $f(x)$ that is defined over a suitable domain around $x=0$ but whose derivative is undefined at $x=0$, one can determine, for $\mathrm{x}$ ranging from -errx to +errx, that the function varies from $\mathrm{f}(-\mathrm{errx})$ to $\mathrm{f}(\mathrm{errx})$. One can then define an "erzatz derivative" equal to the slope of the line joining the points $\{$-errx, $\mathrm{f}(-\mathrm{errx})\}$ and \{errx, $f(e r r x)\}$. Obviously the value of this "derivative" will depend on the value of errx, but when substituted into later formulas requiring a derivative, it will serve the function of relating the variation in the function to the variation in the independent variable.

In general, this erzatz derivative, which we will denote by the symbol $\mathrm{d}^{*} / \mathrm{d}^{*}$, will equal $[\mathrm{f}(\mathrm{errx})-\mathrm{f}(-\mathrm{errx})] /(2 \mathrm{errx})$. In the case of the derivative appearing in Equation 41 , we have

$$
\frac{d * \operatorname{sign} \Delta P_{d h}\left|\Delta P_{d h}\right|^{0.6}}{d * \Delta P_{d h}}=\frac{e r r \Delta P_{d h}^{0.6}-\left(-e r r \Delta P_{d h}\right)^{0.6}}{2 \operatorname{err} \Delta P_{d h}}=\operatorname{err} \Delta P_{d h}^{-0.4}
$$


where by err $\Delta \mathrm{P}_{\mathrm{dh}}^{0.6}$ is meant (err $\left.\Delta \mathrm{P}_{\mathrm{dh}}\right)^{0.6}$, though we will not usually write the parentheses, in the interest of brevity. Substituting this into Equation 41 then yields

$$
\frac{\partial Q}{\partial \Delta P_{d h}} \approx-0.00348 P^{0.6}\left[Q_{25 m e a s}+3.62 Q_{25 i n} e r r \Delta P_{d h}^{-0.4}\right]
$$

We now introduce the quadrature formula for the error in $\mathrm{Q}$ as a function of the errors in the independent variables:

$$
\begin{gathered}
e r r Q=\left[\left(\frac{\partial Q}{\partial Q_{25 \text { meas }}}\right)^{2}\left(e r r Q_{25 \text { meas }}\right)^{2}+\left(\frac{\partial Q}{\partial P}\right)^{2}(e r r P)^{2}+\right. \\
\left.+\left(\frac{\partial Q}{\partial \Delta P_{h a}}\right)^{2}\left(e r r \Delta P_{h a}\right)^{2}+\left(\frac{\partial Q}{\partial \Delta P_{d h}}\right)^{2}\left(e r r \Delta P_{d h}\right)^{2}\right]^{1 / 2}
\end{gathered}
$$

If we now substitute Equations 38, 39, 40, and 43 into Equation 44, and assume that the central or most likely value of $\Delta \mathrm{P}_{\mathrm{dh}}$ is zero, we obtain

$$
\begin{aligned}
e r r Q= & {\left[\left(0.145 P^{0.6}\right)^{2}\left(e r r Q_{25 \text { meas }}\right)^{2}+\right.} \\
& +\left(0.0870 P^{-0.4} Q_{25 \text { meas }}\right)^{2}(e r r P)^{2}+ \\
& +\left(0.00348 P^{0.6} Q_{25 \text { meas }}\right)^{2}\left(e r r \Delta P_{h a}\right)^{2}+ \\
& \left.+\left(0.00348 P^{0.6}\right)^{2}\left(Q_{25 \text { meas }}+3.62 Q_{25 i n} \operatorname{err} \Delta P_{d h}^{-0.4}\right)^{2}\left(e r r \Delta P_{d h}\right)^{2}\right]^{1 / 2}
\end{aligned}
$$

\section{Allowable Errors}

In the same manner as with the house pressure test, with the duct pressurization test we will do a baseline assessment of the relative sizes of errors in each of the independent variables that would be acceptable in practice. We will use Equation 45, and ask what sizes of these errors would produce a specified error in $Q$, if the factor under study were the only source of error. As with the other test, this will give us a way of estimating which of the factors going into the overall error estimate are likely to cause the most trouble. 
By setting all of the independent-variable errors but one in Equation 45 equal to zero in turn and evaluating the resulting error in the remaining independent variable, we obtain the following equations. (Recall that $\mathrm{Q}$ here can be either $\mathrm{Q}_{\mathrm{r}}$ or $\mathrm{Q}_{\mathrm{s}}$ )

$$
\begin{aligned}
& \text { err } Q_{\text {allowed }}=0.145 P^{0.6} \text { err } Q_{25 \text { meas-allowed }} \\
& e r r Q_{\text {allowed }}=0.0870 Q_{25 \text { meas }} P^{-0.4} \mathrm{err} P_{\text {allowed }} \\
& e r r Q_{\text {allowed }}=0.00348 Q_{25 \text { meas }} P^{0.6} \mathrm{err} \Delta P_{\text {ha-allowed }} \\
& \operatorname{err} Q_{\text {allowed }}=0.00348 P^{0.6}\left(Q_{25 \text { meas }}+3.62 Q_{25 i n} \operatorname{err} \Delta P_{d h \text {-allowed }}^{-0.4}\right) \operatorname{err} \Delta P_{\text {dh-allowed }}
\end{aligned}
$$

As with the house pressure test, these equations can be solved for the allowed errors in the independent variables, as functions of the allowed error in $Q$. This is straightforward for the first three:

$$
\begin{aligned}
\text { err } Q_{25 \text { meas-allowed }} & =6.90 P^{-0.6} \mathrm{err} Q_{\text {allowed }} \\
e r r P_{\text {allowed }} & =11.5 P^{0.4} Q_{25 \text { meas }}^{-1} \operatorname{err} Q_{\text {allowed }} \\
\operatorname{err} \Delta P_{\text {ha-allowed }} & =287 P^{-0.6} Q_{25 \text { meas }}^{-1} \operatorname{err} Q_{\text {allowed }}
\end{aligned}
$$

A difficulty arises, however, with the last of the four, namely $\Delta \mathrm{P}_{\text {dhrallowed, }}$, because it appears to the -0.4 power in the parentheses. This results in an equation with the unknown to the 1.0 and 0.6 powers, which is not generally solvable in closed form.

With a reasonable approximation, however, the equation can be transformed into something more tractable. The trick is to assume that $\Delta \mathrm{P}_{\text {dr-2lowed }}$ raised to the 0.1 power is approximately equal to 1 . This is unlikely to cause much error, because $x^{0.1}$ is such a slowly varying function that even if $\mathrm{x}$ is as much as 3 or as little as 0.3 assuming $\mathrm{x}=1$ only introduces an $11 \%$ error in this term.

Formally, we substitute $\gamma=\Delta \mathrm{P}_{\text {dh-allowed }}{ }^{0.1}$ into the last of Equations 14, yielding

$$
79.4 P^{-0.6} \text { err } Q_{\text {allowed }}=\frac{Q_{25 i n} \operatorname{err} \Delta P_{d h \text {-allowed }}^{0.5}}{\gamma}+0.276 Q_{25 \text { meas }} \operatorname{err} \Delta P_{d h \text {-allowed }}
$$


with $\gamma=1$ on the first iteration. This is quadratic in $\Delta \mathrm{P}_{\mathrm{dh}-\mathrm{allowed}}{ }^{0.5}$. As such it has two solutions, but since we need to have the answer come out positive (so we can take its square root) we have

$$
\operatorname{err} \Delta P_{d h-\text { allowed }}^{0.5}=\frac{-Q_{25 \text { in }} / \gamma+\sqrt{Q_{25 \text { in }}^{2} / \gamma^{2}+88 Q_{25 \text { meas }} P^{-0.6} \text { err } Q_{\text {allowed }}}}{0.55 Q_{25 \text { meas }}}
$$

from which the allowed error can easily be calculated:

$$
\operatorname{err} \Delta P_{d h-\text { allowed }}=\left(\frac{-Q_{25 \text { in }} / \gamma+\sqrt{Q_{25 \text { in }}^{2} / \gamma^{2}+88 Q_{25 \text { meas }} P^{-0.6} \text { errQ }} \text { allowed }}{0.55 Q_{25 \text { meas }}}\right)^{2}
$$

\section{Application of the Allowable-Error Criterion to the Four Independent Variables}

Following the argument used with the house pressure test, we will use the criterion that the error in each of the Q's $\left(Q_{r}\right.$ and $\left.Q_{s}\right)$ must be less than $25 \%$ or $50 \mathrm{cfm}$, whichever is larger. With four independent variables, this means that each one may contribute $1 / \sqrt{ } 4$ of this or $12.5 \%$ or $25 \mathrm{cfm}$, whichever is larger.

One simplification here is that we measure the two Q's independently, not together as with the house pressure test. We therefore don't have to worry about what's going on in the return side when we're doing the supply side, and vice versa. approximately by

Allowable Errors in $\mathrm{Q}_{25 \text { meas. }}$ To get the allowed error in $\mathrm{Q}_{25 \text { meas }}$ we note that $\mathrm{Q}$ is given

$$
Q \approx Q_{25 \text { meas }}\left(\frac{P}{25}\right)^{0.6}
$$

and so, when $\mathrm{Q}>200 \mathrm{cfm}$,

$$
\text { err } Q_{\text {allowed }}=0.125 Q=0.0181 Q_{25 \text { meas }} P^{0.6}
$$

Then, using the first of Equations 16,

$$
\text { err } Q_{25 \text { meas-allowed }}=6.90 P^{-0.6}\left(0.018 Q_{25 \text { meas }} P^{0.6}\right)=0.125 Q_{25 \text { meas }}
$$


This should not be a surprising result. When $Q<200 \mathrm{cfm}$, the allowed error in $\mathrm{Q}$ due to errors in this variable is $25 \mathrm{cfm}$, and

$$
e r r Q_{25 \text { meas-allowed }}=172 P^{-0.6}
$$

Note that if $\mathrm{P}=25 \mathrm{~Pa}$, this reduces to $25 \mathrm{cfm}$, as it should, since then $\mathrm{Q}_{25 \text { meas }} \approx \mathrm{Q}$.

A $12.5 \%$ measurement error in flow rate should be achievable. A duct blower manufacturer quotes an accuracy in measured flow rate of $\pm 3 \%$. This, of course, is far from the whole story, yet it does indicate that instrument error is unlikely to be a barrier to these kinds of measurements.

Allowable Error in P. Following the method of the previous section, if Q $>200 \mathrm{cfm}$, then using the second of Equations 47,

$$
\begin{aligned}
\text { errP } P_{\text {allowed }} & =11.5 P^{0.4} Q_{25 \text { meas }}^{-1}\left(0.0181 Q_{25 \text { meas }} P^{0.6}\right) \\
& =0.208 P
\end{aligned}
$$

If $\mathrm{Q}<200 \mathrm{cfm}$, again the allowed error in $\mathrm{Q}$ due to this variable is $25 \mathrm{cfm}$, and

$$
\begin{aligned}
\text { errP } P_{\text {allowed }} & =11.5 P^{0.4} Q_{25 \text { meas }}^{-1}(25) \\
& =288 P^{0.4} \frac{1}{Q}\left(\frac{P}{25}\right)^{0.6} \\
& =\frac{41.7 P}{Q}
\end{aligned}
$$

For $Q=200$, this reduces to $\operatorname{err}_{\text {allowed }}=0.208 \mathrm{P}$, as above, but for $\mathrm{Q}<200$, the allowed error in $\mathrm{P}$ is greater than $0.208 \mathrm{P}$.

The pressure $\mathrm{P}$ in residential ducts will usually fall in the range 20 to $100 \mathrm{~Pa}$, with the supply ducts tending to have somewhat less (absolute value) pressure than the returns. So the allowed error in $\mathrm{P}$ will fall in the range 4 to $20 \mathrm{~Pa}$ for leakage rates above $200 \mathrm{cfm}$, with higher values for lower leakage rates. Achieving this level of measurement precision should not be a problem in most cases.

Allowable Error in $\Delta \mathrm{P}_{\text {ha }}$. Again following the same method, this time with the third of Equations 47, we obtain for the case $Q>200 \mathrm{cfm}$ : 


$$
\begin{aligned}
\text { err } \Delta P_{\text {ha-allowed }} & =287 P^{-0.6} Q_{25 \text { meas }}^{-1}\left(0.0181 Q_{25 \text { meas }} P^{0.6}\right) \\
& =5.2
\end{aligned}
$$

For $\mathrm{Q}<200 \mathrm{cfm}$ :

$$
\begin{aligned}
\operatorname{err} \Delta P_{\text {ha-allowed }} & =287 P^{-0.6} Q_{25 \text { meas }}^{-1}(25) \\
& =7175 P^{-0.6} \frac{1}{Q}\left(\frac{P}{25}\right)^{0.6} \\
& =\frac{1040}{Q}
\end{aligned}
$$

This is always greater than or equal to $5.2 \mathrm{~Pa}$. Thus, the minimum error requirement on $\Delta \mathrm{P}_{\mathrm{ha}}$ is $5.2 \mathrm{~Pa}$. Since blower doors are generally adjusted to within 1 pascal or less of the target pressure difference, this allowable error requirement is easily met.

Allowable Error in $\Delta \mathrm{P}_{\mathrm{dh}}$. Again using the same methods as before, but this time with Equation 50, we obtain, for the case $Q>200 \mathrm{cfm}$,

$$
\begin{aligned}
\text { err } \Delta P_{d h-\text { allowed }} & =\left(\frac{-Q_{25 \text { in }} / \gamma+\sqrt{Q_{25 \text { in }}^{2} / \gamma^{2}+88 Q_{25 \text { meas }} P^{-0.6}\left(0.0181 Q_{25 \text { meas }} P^{0.6}\right)}}{0.55 Q_{25 \text { meas }}}\right)^{2} \\
& =\left(\frac{-Q_{25 \text { in }} / \gamma+\sqrt{Q_{25 i n}^{2} / \gamma^{2}+1.59 Q_{25 \text { meas }}^{2}}}{0.55 Q_{25 \text { meas }}}\right)^{2} \\
& =\left(\frac{-\sigma+\sqrt{\sigma^{2}+1.59}}{0.55}\right)^{2}
\end{aligned}
$$

where $\sigma=Q_{2 \text { sin }} /\left(\gamma Q_{25 \text { meas }}\right)$.

If $\mathrm{Q}<200 \mathrm{cfm}$, then 


$$
\begin{aligned}
\text { err } \Delta P_{d h-a l l o w e d} & =\left(\frac{-Q_{25 \text { in }} / \gamma+\sqrt{Q_{25 \text { in }}^{2} / \gamma^{2}+88 Q_{25 \text { meas }} P^{-0.6}(25)}}{0.55 Q_{25 \text { meas }}}\right)^{2} \\
& =\left(\frac{-\frac{Q_{25 \text { in }}}{\gamma Q_{25 \text { meas }}}+\sqrt{\frac{Q_{25 \text { in }}^{2}}{\gamma^{2} Q_{25 \text { meas }}^{2}}+\frac{2200 Q_{25 \text { meas }}}{P^{0.6}}}}{0.55}\right)^{2} \\
& =\left(\frac{-\sigma+\sqrt{\sigma^{2}+319 / Q}}{0.55}\right)^{2}
\end{aligned}
$$

with $\sigma$ defined as before.

We noted above that these equations could be solved iteratively by putting $\gamma=1$ initially and then, when the first value of $\operatorname{err} \Delta \mathrm{P}_{\mathrm{dh}}$ is obtained, taking that to the 0.1 power to get the next iteration's value of $\gamma$. Convergence is generally obtained very quickly, within two or three iterations. The allowed error is a strong function of $\sigma$. This is to be expected, as this ratio is high when there is a lot of leakage to the inside, just the situation when a nonzero pressure difference between the ducts and the house will lead to significant errors. Some results are as follows:

\begin{tabular}{|c|c|c|}
\hline \multirow{2}{*}{$\begin{array}{l}\text { Ratio of inside to } \\
\text { outside duct leakage } \\
\mathrm{Q}_{25 \text { in }} / \mathrm{Q}_{25 \text { meas }}\end{array}$} & \multicolumn{2}{|c|}{$\begin{array}{l}\text { Allowed Error in Pressure Difference Between the } \\
\text { Ducts and the House: err } \Delta \mathrm{P}_{\text {dh-allowed }} \text { (pascals) }\end{array}$} \\
\cline { 2 - 3 } & $\mathrm{Q}>200 \mathrm{cfm}$ & $\mathrm{Q}=100 \mathrm{cfm}$ \\
\hline 0 & 5.3 & 10.5 \\
\hline 0.5 & 2.6 & 6.7 \\
\hline 1 & 1.3 & 4.1 \\
\hline 2 & 0.4 & 1.7 \\
\hline 5 & 0.05 & 0.2 \\
\hline
\end{tabular}

Most duct systems have much less leakage to the inside than to the outside, with the ratio $Q_{25 \text { in }} / Q_{25 \text { mess }}$ being less than 0.5 and usually 0.2 or less. Unless the ducts are mostly in the conditioned space, meeting the error constraints on $\Delta \mathrm{P}_{\mathrm{dh}}$ should be no problem. 


\section{Summary}

Table 2 presents the allowable errors for each of the four independent variables $\left(Q_{25 \text { meas }}, P, \Delta P_{h a}\right.$, and $\left.\Delta \mathrm{P}_{\mathrm{dh}}\right)$. The criterion of allowable error is the same as that used for the house pressure test. It would appear that meeting the criterion of error should not be difficult, except for ducts whose leakage to the inside greatly exceeds that to the outside.

In view of the perceived difficulties of meeting some of the criteria for the house pressure test, one might be tempted to conclude that fan pressurization is more accurate. While that might be true, it is still possible that systematic biases (which are not captured in this analysis) might skew the results for the fan pressurization test sufficiently that the house pressure test actually is, on average, the more accurate of the two. Thorough investigations of systematic bias in all methods of testing for duct leakage are clearly warranted.

Table 2. Allowed Errors in Independent Variables of Fan Pressurization Test for Duct Leakage

\begin{tabular}{|c|c|c|c|}
\hline \multirow[t]{2}{*}{ Independent Variable } & \multicolumn{2}{|c|}{ Allowable Error } & \multirow{2}{*}{$\begin{array}{l}\text { Difficulty in meeting } \\
\text { error criterion }\end{array}$} \\
\hline & If $Q>200 \mathrm{cfm}$ & If $\mathrm{Q}<200 \mathrm{cfm}$ & \\
\hline $\begin{array}{l}\mathrm{Q}_{25 \text { meas, }} \text { the measured } \\
\text { duct leakage at } 25 \mathrm{~Pa}\end{array}$ & $12.5 \%$ & $\begin{array}{l}>12.5 \% \\
\text { (i.e. less stringent) }\end{array}$ & $\begin{array}{l}\text { Should be easy to } \\
\text { meet. }\end{array}$ \\
\hline $\begin{array}{l}P, \text { the measured } \\
\text { pressure difference } \\
\text { between the ducts and } \\
\text { the outside under } \\
\text { normal operation }\end{array}$ & $21 \%$ & $\begin{array}{l}>21 \% \\
\text { (i.e. less stringent) }\end{array}$ & $\begin{array}{l}\text { Should be easy to } \\
\text { meet. }\end{array}$ \\
\hline $\begin{array}{l}\Delta \mathrm{P}_{\mathrm{ha}} \text {, the house- } \\
\text { ambient pressure } \\
\text { difference produced by } \\
\text { the blower door } \\
\text { (target: } 25 \mathrm{~Pa} \text { ) }\end{array}$ & $5.2 \mathrm{~Pa}$ & $\begin{array}{l}>5.2 \mathrm{~Pa} \\
\text { (i.e. less stringent) }\end{array}$ & $\begin{array}{l}\text { Should be easy to } \\
\text { meet. }\end{array}$ \\
\hline $\begin{array}{l}\Delta \mathrm{P}_{\mathrm{dh}} \text {, the duct-house } \\
\text { pressure difference } \\
\text { produced by the duct } \\
\text { blower (target: } 0 \text { ) }\end{array}$ & $\begin{array}{l}2.6 \mathrm{~Pa} \text { if inside duct } \\
\text { leakage is half that } \\
\text { to outside. } \\
0.4 \mathrm{~Pa} \text { if inside duct } \\
\text { leakage is twice that } \\
\text { to outside. }\end{array}$ & $\begin{array}{l}\text { @ } \mathrm{Q}=100 \mathrm{cfm} \text { : } \\
6.7 \mathrm{~Pa} \text { if inside duct } \\
\text { leakage is half that to } \\
\text { outside, } 1.7 \mathrm{~Pa} \text { if } \\
\text { inside duct leakage is } \\
\text { twice that to outside. }\end{array}$ & $\begin{array}{l}\text { Should be easy to } \\
\text { meet except for } \\
\text { leaky ducts that are } \\
\text { mostly in the } \\
\text { conditioned space. }\end{array}$ \\
\hline
\end{tabular}

Note: In this test it doesn't matter whether the house is tight or leaky. 


\section{REFERENCES}

1. Andrews, J.W. 1996. Field Comparison of Design and Diagnostic Pathways for Duct Efficiency Evaluation. Proc. ACEEE 1996 Summer Study on Energy Efficiency in Buildings, 1:21-30. Washington, D.C.: American Council for an Energy-Efficient Economy.

2. Andrews, J.W., B. Pierce, R. Hedrick, M. Lubliner, B. Reid, and D. Saum. Repeatability of ASHRAE Standard 152P: Results of a Round-Robin Test. BNL Report in press.

3. ASHRAE 1997. A Standard Method of Test for Determining Steady-State and Seasonal Efficiency of Residential Thermal Distribution Systems. Standard 152P. American Society of Heating Refrigerating and Air Conditioning Engineers, Inc., Atlanta, GA.

4. Modera, M. and J. Byrne, 1997. Can a New Duct Test Take the Pressure? Home Energy Magazine, Vol. 14, No. 1 (January/February). 


\section{APPENDIX 1. PATHOLOGICAL BEHAVIOR OF FUNCTIONS $\mathrm{f}, \mathrm{g}, \mathrm{AND} h$}

Examination of the functions $f, g_{R}, g_{s}$, and $h$, as defined in Equations 23 shows that they can behave pathologically under certain conditions. "Pathological behavior" in this case refers to the fact that the functions have singularities, or values of the independent variables for which one or more denominators go to zero, causing the function to be undefined. In the vicinity of these singularities, the function takes on very large values, with large variation within a small range of an independent variable. Such behavior can make them unreliable indicators of the errors they are used to calculate in Equations 24 and 25.

The critical question is this. How large is the range of values of a given independent variable for which this unwanted behavior is experienced? For example, a range of plausible values for $\Delta P_{\text {on }}$ is perhaps from -5 to $+5 \mathrm{~Pa}$. If the subset of values of $\Delta \mathrm{P}_{\mathrm{on}}$ for which the function $\mathrm{f}$ is rapidly varying is a large fraction of this range, then Equations 24 and 25 are not very useful. On the other hand, if the pathological range is very limited, say to a few tenths of a pascal, and if, moreover, there is a reasonable "fix" that can be implemented within this range, then the difficulty is more apparent than real.

The term "pathological behavior" has been used loosely up to this point. It is time to define it more precisely as follows, which we will do by defining its opposite, "normal behavior." A function will be defined as behaving normally or pathologically at each value of the independent variable under consideration. The definition will depend on selection of a "criterion of normality," W, which is discussed more fully below.

For any given value of an independent variable, then, select a restricted domain of that variable centered on the given value and having a width equal to twice the error in the variable. For example, if the given value of $\Delta \mathrm{P}_{\mathrm{on}}$ is denoted by $\Delta \mathrm{P}_{\mathrm{on}-\mathrm{o}}$ the restricted domain of $\Delta \mathrm{P}_{\text {on }}$ will be $\Delta \mathrm{P}_{\mathrm{on}-\mathrm{o}}$ $\operatorname{err} \Delta \mathrm{P}_{\text {on }}<\Delta \mathrm{P}_{\text {on }}<\Delta \mathrm{P}_{\text {on }-\mathrm{o}}+\operatorname{err} \Delta \mathrm{P}_{\text {on }}$.

The next step is to calculate the average value of the function ( $f, g_{R}, g_{S}$, or $h$, as the case may be) over the range of the independent variable as defined above, and compare this with the value of the same function at the central value $\left(\Delta \mathrm{P}_{\text {on-o }}\right.$ in this case $)$.

The function is defined as behaving normally if its value for the given independent variable is within $\mathrm{W}$ percent of its average value over the restricted domain as defined above. If the function is slowly varying, or even if it varies rapidly but linearly, the average value over such a domain will be very close to its value at the midpoint of the domain. However, if the domain includes a singularity, all bets are off.

The above definition is motivated by the realization that the theory of errors using derivatives is only valid if the derivatives are well behaved in the regions of the independent variables that are within error bars of the central or most probable value. If, for example, we calculate an error using the above approach and one of the derivatives happens to have a singularity, that does not mean the 
the error is actually infinite, because as soon as we go away from the singularity by even the slightest amount, the derivative becomes finite. Hence the derivative's value at the central value of the independent variable is not representative of its behavior over the entire domain inside the error bars. More representative would be the function's average value over the domain within the error bars. It should be noted that this average value can be finite even if the domain contains a singularity. And, in fact, for values of $n$ between zero and unity, this will always be the case for the functions ( $f, g_{R}, g_{s}$, and $h$ ).

Selection of Suitable Domains of Independent Variables. Later on, when we consider what magnitude of error in $\Delta \mathrm{P}_{\text {on }}$ can be considered to be "allowed" using reasonable criteria, permissible variations on the order of 0.1 or $0.2 \mathrm{~Pa}$ will generally be found. Although this remains to be seen, in this section we will use 0.1 and $0.2 \mathrm{~Pa}$ as "plausible" errors, on either side of a central value of the independent variable under study.

The f-Function. The first of these functions that we will analyze is the function $f$, defined in Equation 23 as

$$
f=\left|\Delta P_{o n}-2 \Delta P_{o f f}\right|^{n-1}+\left|\Delta P_{o n}\right|^{n-1} \quad(A I-1)
$$

The independent variable whose contribution to the errors in $Q s$ and $Q r$ requires the use of this function is $\Delta \mathrm{P}_{\mathrm{on}}$. This is seen by examining the first term in Equations 24 and 25.

Since $\mathrm{n}<1$ (Standard 152P uses $\mathrm{n}=0.65$ as a typical exponent for envelope air flows), singularities occur when either quantity within absolute value signs is zero, i.e. $\Delta \mathrm{P}_{\text {on }}=2 \Delta \mathrm{P}_{\text {off }}$ and $\Delta \mathrm{P}_{\text {on }}=0$. Figure A-1 shows the behavior of $f$ over a wide range of $\Delta \mathrm{P}_{\text {off }}$ values, for several values of $\Delta \mathrm{P}_{\text {on }}$ as a parameter. Only positive or zero values of $\Delta \mathrm{P}_{\text {on }}$ are studied in this figure, since for negative values of this quantity, the f-function will look the same but reflected about the vertical axis. One can see that, except when $\Delta \mathrm{P}_{\mathrm{on}}=0$, there are two singular points, in the vicinity of which $\mathrm{f}$ takes on very large values. (When $\Delta \mathrm{P}_{\mathrm{on}}=0$ there is only one singularity.)

Figure A-2 shows values of the ratio $f / f_{\text {avg }}$ where $f$ is the value of the function $f$ with the value of plotted on the horizontal axis and the central value of parameterized, while $f_{\text {evg }}$ is the average value of $f$ as varies above and below its given central value by an amount err $\Delta \mathrm{P}_{\text {on }}$. In Figure 2 the value of err $\Delta \mathrm{P}_{\text {on }}$ is 0.2 pascals. 


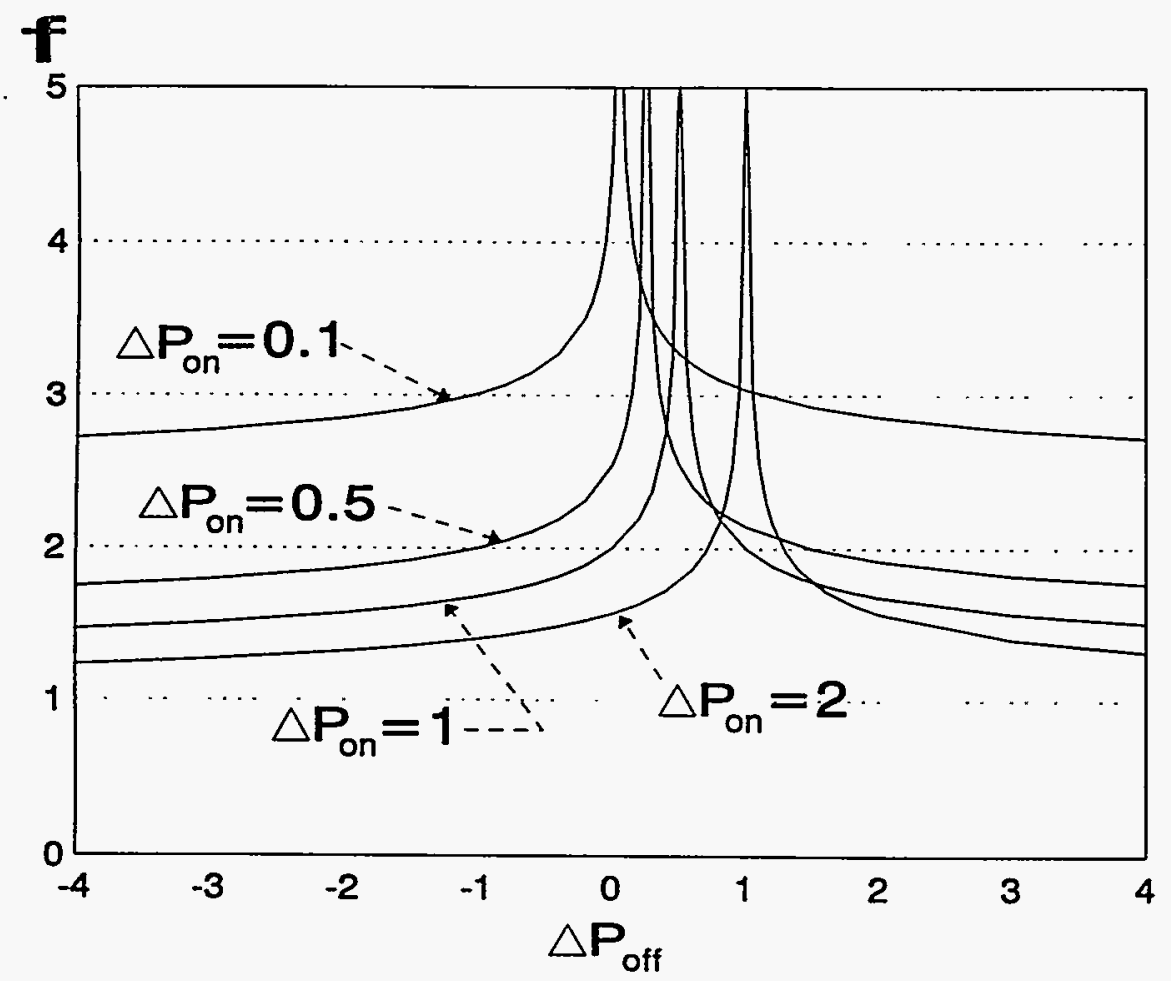

Figure A-1. Behavior of the f-function vs. $\Delta \mathrm{P}_{\text {off }}$ for Various Values of $\Delta \mathrm{P}_{\text {on }}$

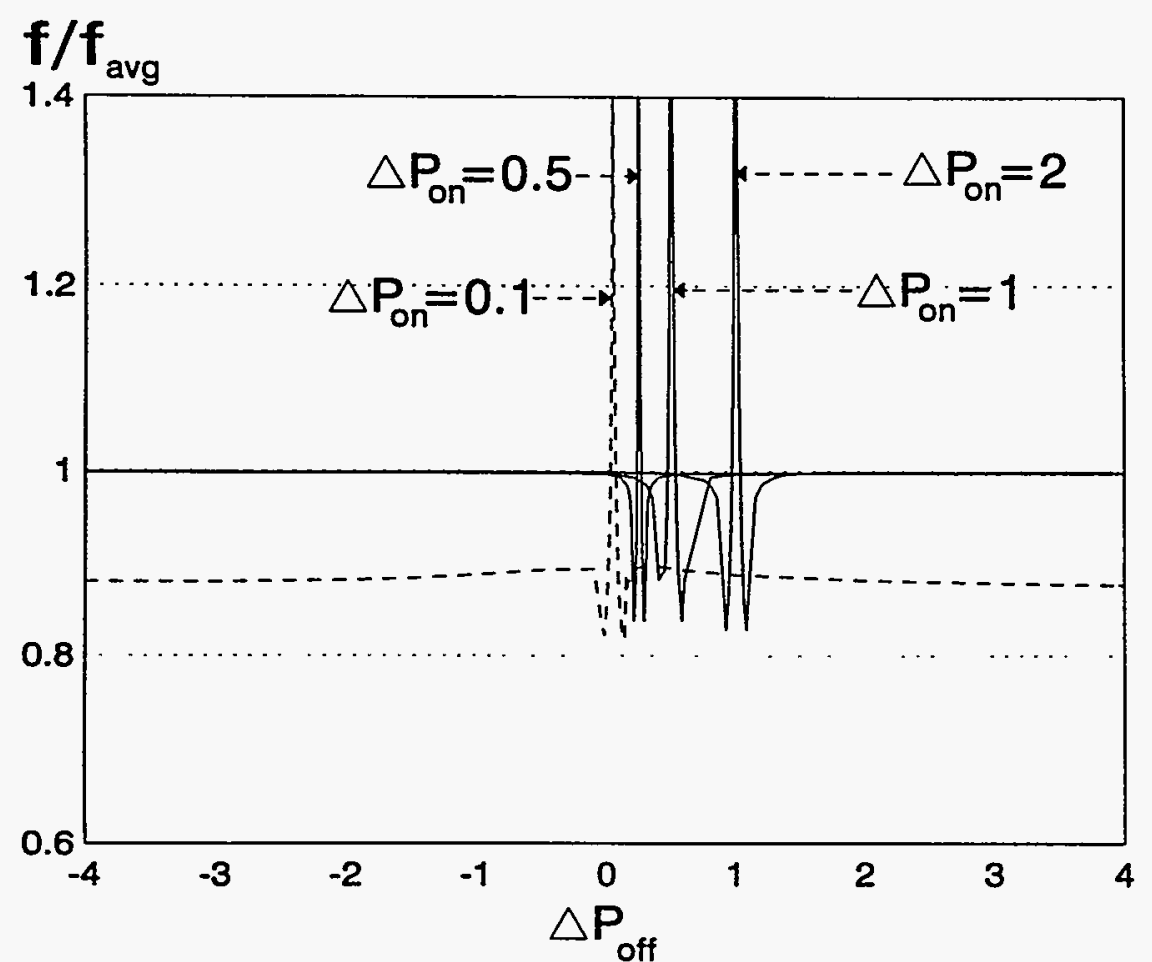

Figure A-2. Ratio of $f\left(\Delta P_{\text {on }}\right)$ to the Average Value of $f$ over the Range $\Delta P_{\text {on }}-0.2$ to $\Delta P_{\text {on }}+0.2$ 
These ratios indicate the amount by which the error in $Q_{s}$ or $Q_{r}$ due to errors in $\Delta P_{\text {on }}$ will be overestimated or underestimated if the function $f$ is used in Equation 28, rather than going all the way back to the definitions of $Q s$ and $Q r$ in Equations 7 and 8. It is apparent that for $\Delta P_{\text {on }}$ values farther from zero than its error (i.e. $0.5,1$, and 2 ) this ratio is extremely close to 1 for almost all values of $\Delta \mathrm{P}_{\text {off }}$. As $\Delta \mathrm{P}_{\text {off }}$ approaches $0.5 \Delta \mathrm{P}_{\text {on }}$, this ratio first dips to about 0.8 , then shoots off to infinity.

This behavior is explained in the following way. For a value of $\Delta \mathrm{P}_{\text {off }}$ that is about one-half to one error bar away from the singularity, the function $f$ underestimates the error because the set of possible values of $\Delta \mathrm{P}_{\text {on }}$ includes the singularity and the high values of $f$ nearby, leading to a higher average. On the other hand, when $\Delta \mathrm{P}_{\text {off }}$ is very close to the singularity, its value can be quite high, and yet the average will include lower values of $f$ farther from the singularity.

Stated in simple terms, using the function $\mathrm{f}$ in the error calculations is almost always a very good approximation, good to within $1 \%$. As a singularity is approached, however, the function $f$ first can underestimate the error by as much as $20 \%$, then turns around and can overestimate it by an unlimited amount if the values of $\Delta \mathrm{P}_{\text {on }}$ and $\Delta \mathrm{P}_{\text {off }}$ are extremely close to the singularity. (Again, being close to the singularity means $\Delta \mathrm{P}_{\text {on }}$ and $\Delta \mathrm{P}_{\text {off }}$ having values that make one of the absolute values in the function $f$ get very close to zero.

So how close is close? The answer is that as long as the quantities $\Delta \mathrm{P}_{\text {on }}$ and $\Delta \mathrm{P}_{\text {on }}-2 \Delta \mathrm{P}_{\text {off }}$ are at least 0.1 pascal away from zero, the use of the function $f$ will not produce more than about a $20 \%$ overestimate or underestimate of the error due to errors in $\Delta \mathrm{P}_{0 \mathrm{v}}$ and will almost always be much more accurate than this. The possibility of being so close to a singularity as to drastically overestimate the error (or have fundefined if the input values are exactly at a singularity) can be dealt with by the following proviso: the value of $f$ shall be limited to no more than 4 , in units of $\mathrm{Pa}^{-0.35}$.

And so, boiling this down even further, we redefine the function $f$ as follows: Compute $f$ according to the first of Equations 23 . If its value is greater than 4 , or if it is undefined, set it equal to 4 .

Another good thing that should be pointed is that because $\Delta \mathrm{P}_{\text {on }}$ is only one of six sources of error, combining according to the quadrature law, even if we are close to a singularity for the $f$ function, the actual overestimation or underestimation of $Q_{r}$ and $Q_{S}$ will usually be quite small because of the addition of errors in quadrature.

The h-Function. Examination of Equations 23 shows that the h-function has the same form in the independent variable $\Delta \mathrm{P}_{\mathrm{RB}}$ that the $\mathrm{f}$-function has in the independent variable $\Delta \mathrm{P}_{\text {on }}$. So Figure A-1 can be used to visualize the behavior of $h$ if $\Delta \mathrm{P}_{\mathrm{RB}}$ is substituted for $\Delta \mathrm{P}_{\text {on }}$ as the parameter. Therefore, whatever conclusions are valid for $f$ and $\Delta P_{\text {on }}$ are also valid for $h$ and $\Delta P_{R B}$. So we conclude immediately that in calculating the error in $Q_{s}$ and $Q_{r}$ due to errors in $\Delta P_{R B}$, use $h$ as calculated unless it exceeds 4 or is undefined, in which case the value 4 is to be used. 
The g-Functions. The g-functions, which govern the errors in $\mathrm{Q}_{s}$ and $\mathrm{Q}_{\mathrm{r}}$ due to error in $\Delta \mathrm{P}_{\text {off }}$ are more complicated beasts, for two reasons. First, they incorporate both $\Delta \mathrm{P}_{\text {on }}$ and $\Delta \mathrm{P}_{\mathrm{RB}}$, and not just one or the other as is the case with $f$ and $h$. Second, they also incorporate either $S$ or $R$. Thus, instead of one independent variable and one parameter, as in the case of $f$ and $h$, we have one independent variable $\left(\Delta \mathrm{P}_{\text {off }}\right.$ in this case $)$ and three parameters $\left(\Delta \mathrm{P}_{\mathrm{on}}, \Delta \mathrm{P}_{\mathrm{RB}}\right.$, and either $\mathrm{R}$ or $\left.\mathrm{S}\right)$.

Figures A-3 and A-4 show the variation of the functions $g_{R}$ and $g_{s}$ for a representative value of $\Delta \mathrm{P}_{\mathrm{on}}=-1$ and three compatible values of $\Delta \mathrm{P}_{\mathrm{RB}}(0,1$, and 2$)$, with typical values of $\mathrm{S}$ and $\mathrm{R}$ equal to 0.8 and 1.6 , respectively. Like $f$, this function has singularities around which it "goes off to infinity," and broad regions of the independent variable over which it varies slowly.

It should be noted that, in general, because the g-functions are built up from a difference of two absolute values, they tend to have smaller values than $f$ or $h$, which are sums. This reduces the size of the error in $\mathrm{Q}_{\mathrm{S}}$ and $\mathrm{Q}_{\mathrm{r}}$ that is due to $\Delta \mathrm{P}_{\text {off }}$. However, for some values of the three pressure differences, one will be near a singularity and then the contribution of $\Delta P_{\text {off }}$ to the errors in the $Q$ 's will be large.

We have yet to perform integrals over variations in $\Delta \mathrm{P}_{\text {off }}$ analogous to what we did for the independent variable $\Delta \mathrm{P}_{\text {on }}$ in the function $\mathrm{f}$. For now, it is recommended that the calculated values of $g$-functions be used unless they should be greater than 4 . This will seldom happen.

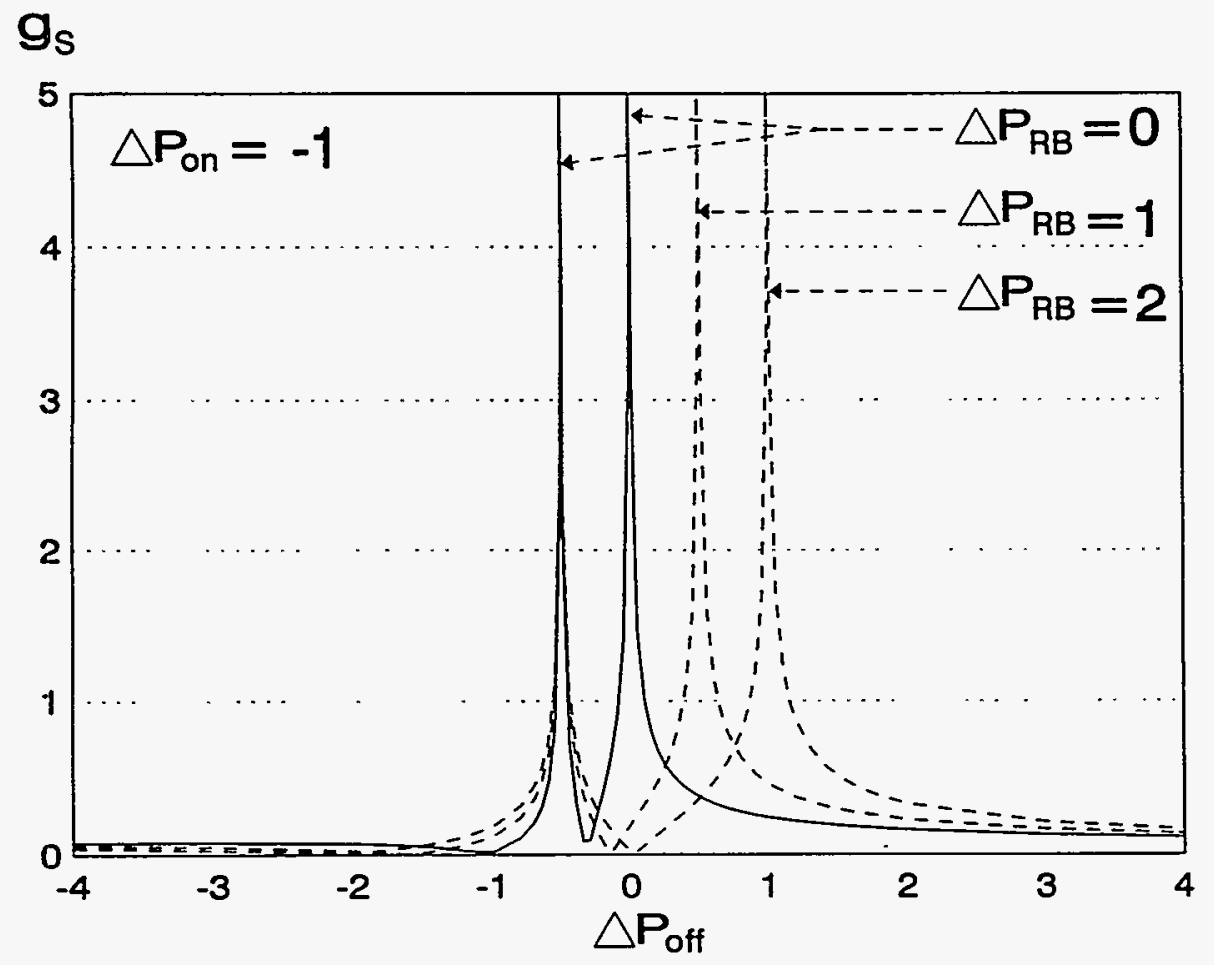

Figure A-3. Behavior of $g_{s}$ vs. $\Delta \mathrm{P}_{\text {off }}$ for Various Values of $\Delta \mathrm{P}_{\mathrm{RB}}$, with $\Delta \mathrm{P}_{\text {on }}$ Fixed at $-1 \mathrm{~Pa}$. 


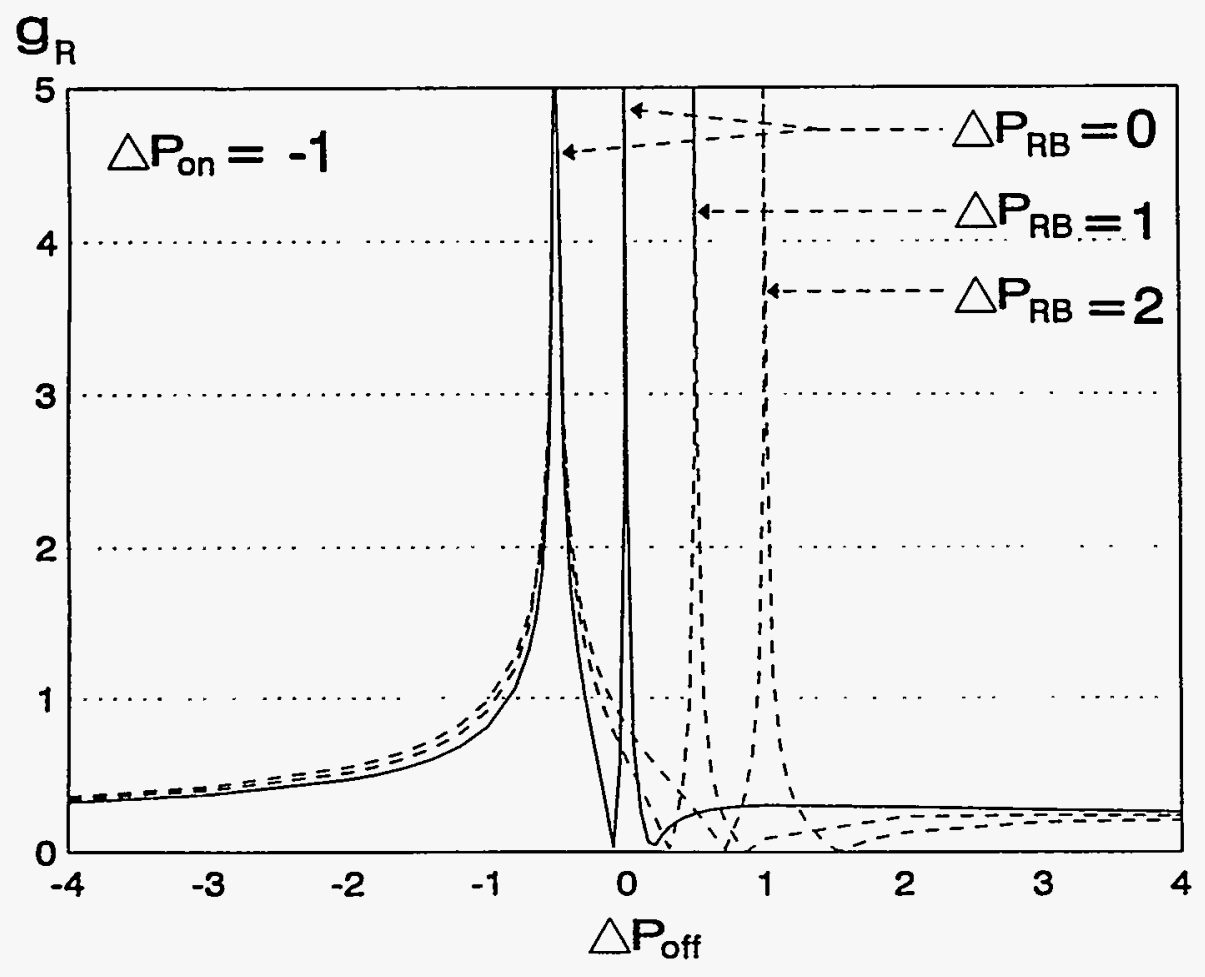

Figure A-4. Behavior of $g_{R}$ vs. for Various Values of $\Delta P_{R B}$, with $\Delta P_{\text {on }}$ Fixed at -1 Pa. 